\title{
ARTÍCULOS
}

\section{CUBA, LA ISLA DEL RAYO VERDE EN LA DINÁMICA DE LAS RELACIONES EXTERIORES DE ITALIA. DE LA MARCHA SOBRE ROMA A LA SEGUNDA GUERRA MUNDIAL'.}

\author{
Alberto Consuegra Sanfiel \\ Universidad Nacional de La Plata \\ albertoconsuegra@yahoo.es
}

Resumen: El artículo tiene como objetivo principal reconstruir y analizar, a través de fuentes documentales y periodísticas, los rasgos distintivos que adquirieron las relaciones económicas y políticas desarrolladas entre Italia y Cuba entre 1922 y 1941. Además de exponer los cambios y continuidades que se dieron durante el período, se intenta demostrar la importancia que tuvo Cuba para la agenda exterior italiana, además de que aporta conocimiento a la producción historiográfica acerca de las relaciones diplomáticas cubanas durante la época republicana. Asimismo, se presenta la importancia de la exigua comunidad de inmigrantes italianos en el desarrollo y consolidación de las relaciones entre ambos países, y el desempeño que tuvo la legación italiana en la implementación de un programa cultural que descansó en la exaltación de la latinidad como lazo cultural en la promoción del fascismo como corriente ideológica.

Palabras clave: Cuba, Italia, relaciones exteriores, diplomacia, fascismo, propaganda.

Tittle: CUBA, THE GREEN LIGHTNING ISLAND, IN THE DYNAMICS OF THE FOREIGN RELATIONS OF ITALY. FROM THE MARCH ON ROME TO WORLD WAR II.

Abstract: The main objective of the article is to reconstruct and analyze, through documentary and journalistic sources, the distinctive features that acquired the economic and political relations developed between Italy and Cuba between 1922 and 1941. In addition to exposing the changes and continuities that occurred during this period, it is tried to demonstrate the importance that Cuba had for the Italian foreign agenda, in addition to providing knowledge to the historiographical production about cuban diplomatic relations during the republican era. Likewise, the importance of the small community of italian immigrants in the development and consolidation of relations between the two countries is presented, and the performance of the italian legation in the implementation of a cultural program that rested on the exaltation of latinity as a link cultural in the promotion of Fascism as an ideological current.

Keywords: Cuba, Italy, foreign relations, diplomacy, fascism, propaganda.

\footnotetext{
1 De esta manera se refirió Mario Apellius sobre Cuba en su libro La Isla del rayo verde: CubaJamaica- Puerto Rico-Haití-Pequeñas Antillas. Barcelona: Editorial Maucci, 1929.
}

Cómo citar este artículo: CONSUEGRA SANFIEL, Alberto. Cuba, La Isla del rayo verde en la dinámica de las relaciones exteriores de Italia. De la marcha sobre Rome a la Segunda Guerra Mundial. Naveg@mérica. Revista electrónica editada por la Asociación Española de Americanistas [en línea]. 2020, n. 25. Disponible en: <http://revistas.um.es/navegamerica>. [Consulta: Fecha de consulta]. ISSN 1989-211X. 


\section{Introducción}

Los vínculos políticos, culturales, económicos y diplomáticos que estableció Cuba con otros países antes de 1959 -exceptuando con Estados Unidos- es un tema que no ha sido abordado en profundidad ni por los historiadores locales ni por aquellos de otras latitudes que han mostrado interés por la historia del país caribeño. Grosso modo, los criterios políticos-ideológicos impuestos por el gobierno revolucionario después de 1959 para hacer historia en función, precisamente, de poner dicha ciencia al servicio del proceso transformador que se inició durante los años de 1960, hizo que determinados temas y períodos fueran obviados y/o abordados de manera diferente. Se enclaustró así el quehacer y el saber histórico en esquemas ideológicos que nada tuvieron que ver con el desarrollo de las Ciencias Sociales a nivel regional y mundial ${ }^{2}$. Por ejemplo, un período crucial como la década de 1930 ha sido explicada y mostrada, en sentido general, como parte del mismo ciclo revolucionario que se inició en 1868 y culminó en 1959, y se ha hecho mayor énfasis en el estampido revolucionario que hizo caer el gobierno de Machado y en el proceso político-social previo a la Constitución de 1940, en detrimento de otras cuestiones que podrían hacer más próspero el acercamiento al período.

Y es que la década de 1930 fue para Cuba, como para todos los países de la región, un período marcado por convulsiones políticas, sociales y económicas que transformaron los cimientos de la sociedad. Sumergida en una profunda crisis económica y estremecida, además, por la gran estampida social que terminó con el Machadato, la sociedad cubana padeció con carácter prolongado los efectos de la Gran Depresión de 1929-33 hasta casi entrados los años de 1940, sumado a los resultados negativos que arrojó la política económica del gobierno de Gerardo Machado (1925-1933). Así, lo cierto es que la recepción en Cuba de corrientes ideológicas como el fascismo, unido a algunos conflictos internacionales que se dieron durante la segunda mitad de la década de 1930, en especial el Segundo Conflicto Ítalo-etíope y la Guerra Civil española, estuvo atravesado por varios factores que moldearon las diferentes manifestaciones que se suscitaron, dándole una impronta propia que hizo que se diferenciara de las expresiones que se sucedieron en el resto de la región.

La política exterior de la Italia fascista para con el continente americano será uno de los elementos que influirá, indefectiblemente, en la postura política y social de los gobiernos y las sociedades latinoamericanas para con Italia, sobre todo en lo referido a las interpretaciones, usos y adaptaciones que se le dará al fascismo como corriente ideológica. Precisamente, el presente artículo intenta explorar y analizar cómo se desarrollaron las relaciones entre Italia y Cuba a partir de la dinámica de política exterior trazada por Roma, lo cual fue un factor determinante que permitiría medir el grado de acercamiento que tuvo el Estado cubano con el régimen fascista,

2 ROJAS, Rafael. Caminos de la historia crítica. Cuban Studies. 2015, n. 43, pp. 135-140; ROJAS, Rafael. El nuevo texto de la Revolución. En: LLANO PULIDO, G.; AYALA, M. y CONSUEGRA SANFIEL, A. Mirando a Cuba. Reformas y configuraciones en una nueva etapa. Buenos Aires: Imago Mundi, 2016, pp. 1- 12; IBARRA, Jorge. Historiografía y Revolución. Temas. Ene./Mar. 1995, n. 1, pp. 4-14; LEPKOWSKI, Tadeusz. Problemas controvertibles de una síntesis de la historia de Cuba. Estudios Latinoamericanos. 1972, n.1, pp. 101-154; LARA, Martín. Historiografía cubana. Entrevista a Óscar Zanetti Lecuona. RIRA. Oct. 2016, vol. 1, n. 2, 2016, pp. 201-213. 
la verdadera influencia que tuvo el fascismo en los debates políticos y sociales que se dieron en el período, así como los cambios o no que se dieron desde el ascenso del fascismo hasta la entrada de Cuba a la Segunda Guerra Mundial.

Si bien quienes concordaron con el falangismo en Cuba, en sentido general, fueron los mismos actores que comulgaron con el fascismo italiano, es importante aclarar que el presente artículo no busca establecer paralelismos, y mucho menos centra su análisis en los vínculos y/o préstamos ideológicos entre ambos movimientos políticos. La investigación, exclusivamente, pretende esbozar las relaciones políticas, diplomáticas y económicas entre Cuba e Italia (1935-1941) reconociendo, también, las limitaciones documentales que presenta el tema. Además de la distancia geográfica, por razones que se desconocen, en los archivos cubanos no existen registros que permitan extraer información sobre las relaciones entre Italia y Cuba antes de 1959, mientras que las únicas fuentes primarias que habría están en el Archivo del Ministerio de Relaciones Exteriores de Italia. Ante esta situación, la reconstrucción y análisis de los vínculos entre ambas naciones se hizo a partir de la revisión de documentos secundarios, como la prensa cubana de la época, publicaciones oficiales específicas de los gobiernos de Cuba y de Italia, así como otras producciones que de alguna forma $u$ otra aportan datos que complementan la información.

\section{Negocios, cultura y viajes: las relaciones entre Italia y Cuba (1922-1937)}

Si bien la publicación de las ideas de Joseph Nye sobre el ejercicio del "poder suave" (soft power) introdujo nuevas miradas en el análisis de las relaciones internacionales desde $1990^{3}$, lo cierto es que el ejercicio del llamado "poder suave" en los vínculos interestatales no es un fenómeno de los últimos años. Tanto el despliegue de la política exterior francesa en el siglo XIX, cuando buscó promover su lengua y la literatura a través de la Alliance Française, o la política que proyectó la Alemania nazi para con los países europeos y americanos a través de la radio y los filmes ${ }^{4}$, son ejemplos que demuestran cómo distintos gobiernos han proyectado una agenda exterior basada en la emulación de sus logros y la promoción de sus valores a lo largo de la historia. En todos los casos, dichos lazos diplomáticos, culturales y/o políticos se han construido sobre la necesidad de cooptar, en el caso de quienes los conciben, a actores internacionales para sumar aliados y/o conseguir resultados beneficiosos 5 .

En palabras del propio Nye, el poder suave es “(...) la habilidad de un país de estructurar una situación para que otros países desarrollen preferencias o definan sus intereses de tal forma que concuerden con los propios. Este poder tiene a surgir de fuentes tales como la atracción cultural e ideológica tanto como de reglas e

\footnotetext{
${ }^{3}$ NYE, Joseph S. The Changing Nature of World Power. Political Science Quarterly. 1990, vol. 105, n. 2, pp. 177-192.

${ }^{4}$ Consultar: FOX, J.C. Film propaganda in Britain and Nazi Germany: World War II cinema. Oxford: Berg, 2007; MONTES PÉREZ, Carlos. Cuerpos representados, cuerpos dominados. Poder y representación en los carteles de propaganda nazi Thémata. Revista de Filosofía. 2012, n. 46, pp. 707-716.

${ }^{5}$ NYE, Joseph S. Soft power. The means to success in World Politics. Nueva York: PublicAffairs, 2004 , p. 5.
} 
instituciones de regímenes internacionales (..."․․ Precisamente, los vínculos políticos, económicos y culturales que se establecieron entre Italia y Cuba desde 1922 hasta 1941 revistieron dicho carácter por parte de Italia, y fue uno de factores centrales que coadyuvaron a instalar el fascismo como ideología y posible modelo a seguir en el debate político y social cubano de los años 30, sobre todo en el momento de mayor protagonismo de Italia en la escena internacional a partir de su participación directa en el Segundo Conflicto Ítalo-etíope y en la Guerra Civil española.

Insertos en la agenda exterior, lo cierto es que los lazos que se fueron tejiendo entre Roma y el país caribeño no siempre respondieron a las generalidades de la relaciones diplomáticas, políticas y culturales que proyectó Italia para con la región, donde las prioridades estuvieron centradas en aquellos países donde se habían asentado gran número de inmigrantes italianos ${ }^{7}$. A partir del análisis de las relaciones que cultivaron ambos países se podría afirmar, primero, que el país europeo mostró siempre interés por acercarse a Cuba, y segundo, que los distintos gobiernos cubanos que se sucedieron durante el período entre 1922 y 1941 mantuvieron una relación de cordialidad respecto al gobierno italiano, más allá de que hubo momentos de acercamientos y distanciamientos los cuales respondieron, casi siempre, a los avatares internacionales del momento.

La primera muestra de acercamiento que tuvo el gobierno fascista italiano para con Cuba se dio cuando incluyó al puerto de La Habana en el recorrido que daría por Latinoamérica el barco Italia ${ }^{8}$. Con aproximadamente 700 italianos a bordo, la mayoría de ellos representantes de empresas industriales, grandes comerciantes, artistas, militares y periodistas, el buque visitó varios países de la región durante el año 1924 con el objetivo de promocionar el régimen fascista en la región, además de establecer relaciones comerciales ${ }^{9}$.

\footnotetext{
${ }^{6}$ Ibídem, p. 77.

7 SAVARINO, Franco. Apuntes sobre el fascismo italiano en América Latina (1922- 1940). Reflejos, Revista de la Universidad de Jerusalén. 2000-2001, n. 9, pp. 100-110.

${ }^{8}$ DÍAZ MARTÍN, Roberto. Etapas en Cuba de cruceros históricos italianos en los años 20 del siglo XX. El Barco "Italia" y el vuelo de Francesco Pinedo. En: CAMPOLONGO, D. Emigrazione y presenza italiana in Cuba. Vol. VII. Circolo culturale B.G. Duns Scoto, 2005, pp. 121- 134.

9 lbídem, pp. 121-134.
} 


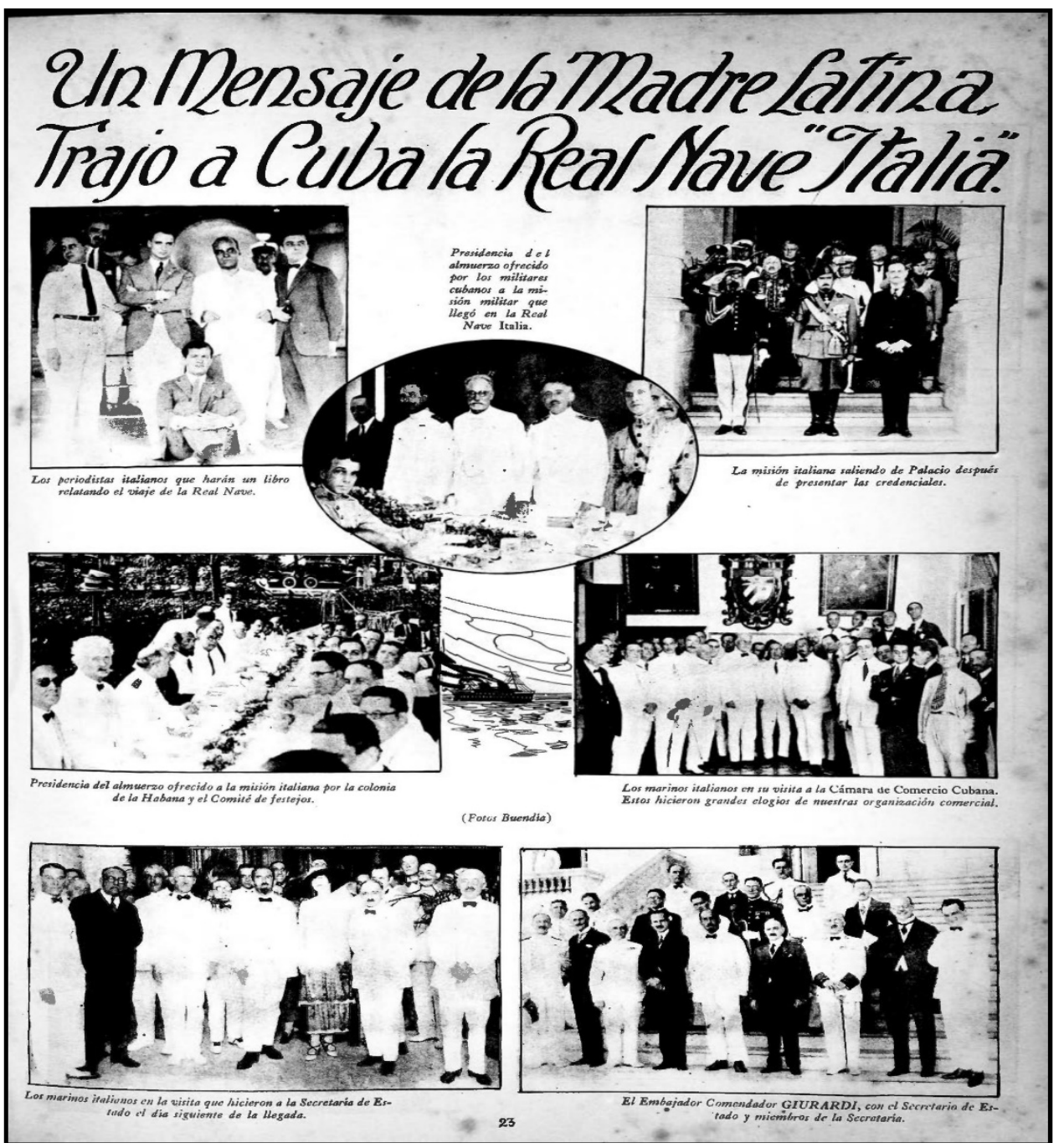

Fig. 1: Visita del barco Italia, 1924. Fuente: Revista Carteles, La Habana, 14 de septiembre, 1924, p. 23. Biblioteca Nacional de Cuba "José Martí".

En el caso de la visita a Cuba, a pesar de que se dieron incidentes y actos de desagravio por parte de organizaciones obreras y estudiantiles ${ }^{10}$, lo cierto es que la comitiva italiana tuvo un cálido recibimiento por las autoridades nacionales, las del municipio de La Habana, así como el cuerpo diplomático y la pequeña comunidad de italianos asentada en la capital ${ }^{11}$. Durante los días que estuvo anclado el barco en el

\footnotetext{
${ }^{10}$ Desde antes y durante la llegada del barco a Cuba, organizaciones obreras y estudiantiles liderada por Julio Antonio Mella, se habían organizado para efectuar actos de repudio contra la delegación italiana. Con el título de "La juventud estudiosa contra los asesinos y tiranos de Italia", Mella había escrito y divulgado un llamamiento que convocaba al boicot de la delegación, recordando la muerte Giacomo Matteotti a manos de Mussolini. MELLA, Julio Antonio. Documentos y artículos. La Habana: Editorial Ciencias Sociales, 1975, pp. 109-111. Esto se tradujo en concentraciones frente al puerto habanero, así como la negativa de los trabajadores portuarios, por ejemplo, en la carga y descarga del buque. GONZÁLEZ, Froilán y CUPULL, Adys. Julio Antonio Mella y Tina Modotti contra el Fascismo. Ciudad de La Habana: Casa Editora Abril, 2005, p. 12.

${ }^{11}$ La delegación del barco Italia participó en un conjunto de actividades entre las que se destacaron la visita a la Secretaría de Estado, la presentación de las cartas credencias por parte del embajador extraordinario Giovanni Giuriati ante el presidente de Cuba, Dr. Alfredo Zayas, la visita a la alcaldía de La Habana, el banquete ofrecido en los Jardines de La Tropical en nombre de la comunidad italiana, y
} 
puerto de La Habana, además, la prensa cubana que comulgaba con el fascismo estuvo atenta a cada uno de los actos programados en los que participó la delegación italiana, e intentó en cada editorial publicada minimizar el repudio manifiesto que hicieran las organizaciones obreras y estudiantiles desde mucho antes del arribo de la delegación. Amplios fueron los textos periodísticos que hicieron énfasis en los lazos históricos que habían unido a los dos países, en especial, durante los años de las guerras independentistas, período que estaba aún vivo en la memoria colectiva de la sociedad cubana ${ }^{12}$.

Siguiendo las declaraciones que hizo Carlos Arnoldson, presidente de la Cámara de Comercio e Industria de la isla de Cuba en la recepción que preparó la Secretaría de Estado a la comitiva italiana, tanto los industriales como las autoridades políticas se mostraron alineados con las expectativas que traía la comitiva, de establecer lazos económicos y comerciales, además de que ratificaron públicamente la disposición por parte del sector económico y político cubano a efectivizar un acercamiento económico y comercial con Italia ${ }^{13}$. Más allá que el orador utilizó un lenguaje protocolar y lleno de alabanzas para con los visitantes, es importante destacar que su discurso estuvo en correspondencia con los intereses que en política exterior había comenzado a perfilar Italia para con los países latinoamericanos. Mostraba, a su vez, la posición que asumiría el gobierno cubano en el plano político y económico respecto a Italia, ya que era una recepción oficial donde estaban, según la prensa, el secretario de Agricultura, Industria y Comercio, además que el destino que tomara la institución que dirigía Arnoldson coincidía con la política económica del país ${ }^{14}$.

Frente al embajador Giuriati, máxima autoridad del grupo visitante, el presidente de la Cámara expresó:

\begin{abstract}
"Queremos en estos momento afirmar el acercamiento de relaciones comerciales entre Italia y Cuba de una manera efectiva (...) Cuba, país excepcionalmente dotado por la naturaleza, colocado en situación geográfica inmejorable, a la entrada del Golfo de México, Diosa del Caribe, se encuentra en medio de dos civilizaciones como puente que une a las dos Américas, nos encontramos entre la civilización suramericana y la civilización norteamericana, entre el progreso latino y el avance sajón, y esta Cuba privilegiada, la que tiene el honor de recibiros en estos instantes, tendiéndonos la mano, para que un futuro próximo nuestra simpatía espiritual se traduzca en bien material entre ambos países (...). Aspiramos, ilustre Embajador, a que vuestra visita se traduzca en hechos tangibles y que los entusiasmos del momento no se concreten únicamente a las visitas y a los homenajes oficiales, queremos que cuando regreséis a vuestro país, expongáis que en el Continente Americano, y como avanzada de la unión de ambas Américas, hay un pueblo, pequeño, heroico, laborioso e inteligente que desea estrechar vínculos con la madre de la civilización latina, queremos, en una palabra, afirmar el concepto de la latinidad (...)"15.
\end{abstract}

la función de gala que se ofreció para la comitiva en el Teatro Nacional. DÍAZ MARTíN, Roberto. Etapas en Cuba... Op. cit., p. 127.

12 GONZÁLEZ, Froilán y CUPULL, Adys. Julio Antonio Mella... Op. cit., p. 28.

${ }^{13}$ Diario de La Marina, La Habana, 5 de septiembre, 1924, p. 1.

${ }^{14}$ GONZÁLEZ, Froilán y CUPULL, Adys. Julio Antonio Mella... Op. cit., p. 36.

15 Diario de La Marina, La Habana, 5 de septiembre, 1924, p. 1. 
Aunque no existen documentos que lo confirmen, las coincidencias entre el discurso pronunciado por la parte cubana y los argumentos sobre los cuales descansaba la política exterior italiana para acercarse a América, daban cuenta de la admiración temprana que sentía una parte importante de los grupos económicos cubanos por Italia, y por consecuencia, por el fascismo como modelo político, además de los estrechos vínculos que había entre la exigua pero influyente comunidad italiana en Cuba, la alta burguesía y el fasci habanero ${ }^{16}$.

Precisamente, los dirigentes e integrantes de dicha organización en Cuba se hicieron presente en todos los actos oficiales y aprovecharon la ocasión para hacer proselitismo al interior de la comunidad de italianos. Como sucedió en los 23 puertos que tocara la nave, la visita significó un reconocimiento o realce de carácter nacionalista que incrementó el orgullo de pertenencia a una raza que ahora se mostraba como única, y por sobre todas las cosas, les permitió obtener cierto grado de visibilidad como inmigrantes en un país en el que eran minoría. Si bien el fasci de La Habana no tuvo nunca las dimensiones de su par argentino o el brasileño, lo cierto que se caracterizó por ser una organización que supo establecer vínculos fuertes con los sectores políticos, económicos y culturales en la isla, relaciones que le permitieron cierto grado de visibilización en actividades de muy alto nivel en calidad de representantes del Partido Nacional Fascista (PNF), como en la visita del barco Italia, o en el recibimiento que se le diera más tarde, en 1927, al piloto Francesco de Pinedo cuando también hizo una parada en Cuba mientras hacía el vuelo trasatlántico ${ }^{17}$. Además, coordinó sendas actividades culturales que tuvieron resonancia y fueron publicitadas, casi siempre, en la prensa más influyente del momento.

Un ejemplo de los vínculos e influencias que desarrolló la organización fascista en Cuba se pueden apreciar a partir de las propias declaraciones que hicieron en 1927 el presidente y el secretario de ese entonces, Michele de Luca y Attilio de Gregorio, cuando fueron conminados por las autoridades cubanas a desistir de actitudes violentas y amenazantes contra sus connacionales con el objetivo de ganar

\footnotetext{
${ }^{16}$ Los fasci fueron asociaciones de italianos que surgieron desde el fin de la Gran Guerra Mundial y que más tarde, con la llegada del fascismo, fueron cooptados por el partido, convirtiéndolos en una especie de "little italies" que respondieron a la propaganda de Roma. FABIANO, D. I fasci italiani all'estero. En: BEZZA, B. (ed.). Gli italiani fuori d'Italia. Gli emigrati italiani nei movimenti operai dei paesi d'adozione. Milan: Angeli, 1983, p .224. En casi todas las actividades en las que participó la delegación italiana, estuvieron presentes figuras importantes de la burguesía habanera, entre los que se destacaban periodistas y directores de periódicos importantes, como José I. Rivero, director del Diario de La Marina y Tomás Juliá, director de La Discusión, así como personalidades de la política como Orestes Ferrara. Este último, además de ser italiano de nacimiento, era uno de los empresarios más poderosos del país y ocupaba en ese momento un cargo en la Cámara de Representantes, era profesor en la Universidad de La Habana, y tenía estrechos vínculos con el gobierno. DÍAZ MARTíN, Roberto. Etapas en Cuba... Op. cit., p. 127. GONZÁLEZ, Froilán y CUPULL, Adys. Julio Antonio Mella... Op. cit., pp. 40-43.

17 Los vuelos de largo alcance fue otros de los métodos que utilizó Mussolini para mostrar los logros que en materia de aviación y poderío militar que habían alcanzado, y por supuesto, buscar admiración y seguidores de la ideología fascista, en especial a los inmigrantes italianos diseminados por el mundo. Así, durante la década de 1920 y 1930 se sucedieron importantes vuelos trasatlánticos a América y a Asia. En este caso, era el segundo DÍAZ MARTíN, Roberto. Etapas en Cuba... Op. cit., pp. 130-131.
} 
las elecciones de la organización. Denunciados por los propios vecinos, ya que habían provocado un gran disturbio, los mencionados dirigentes declararon a la prensa que "(...) sus influencias secretas con sectores importantes de la sociedad cubana en la esfera gubernamental, especialmente en los órganos policíacos, les permitía actuar en La Habana de manera impune"18.

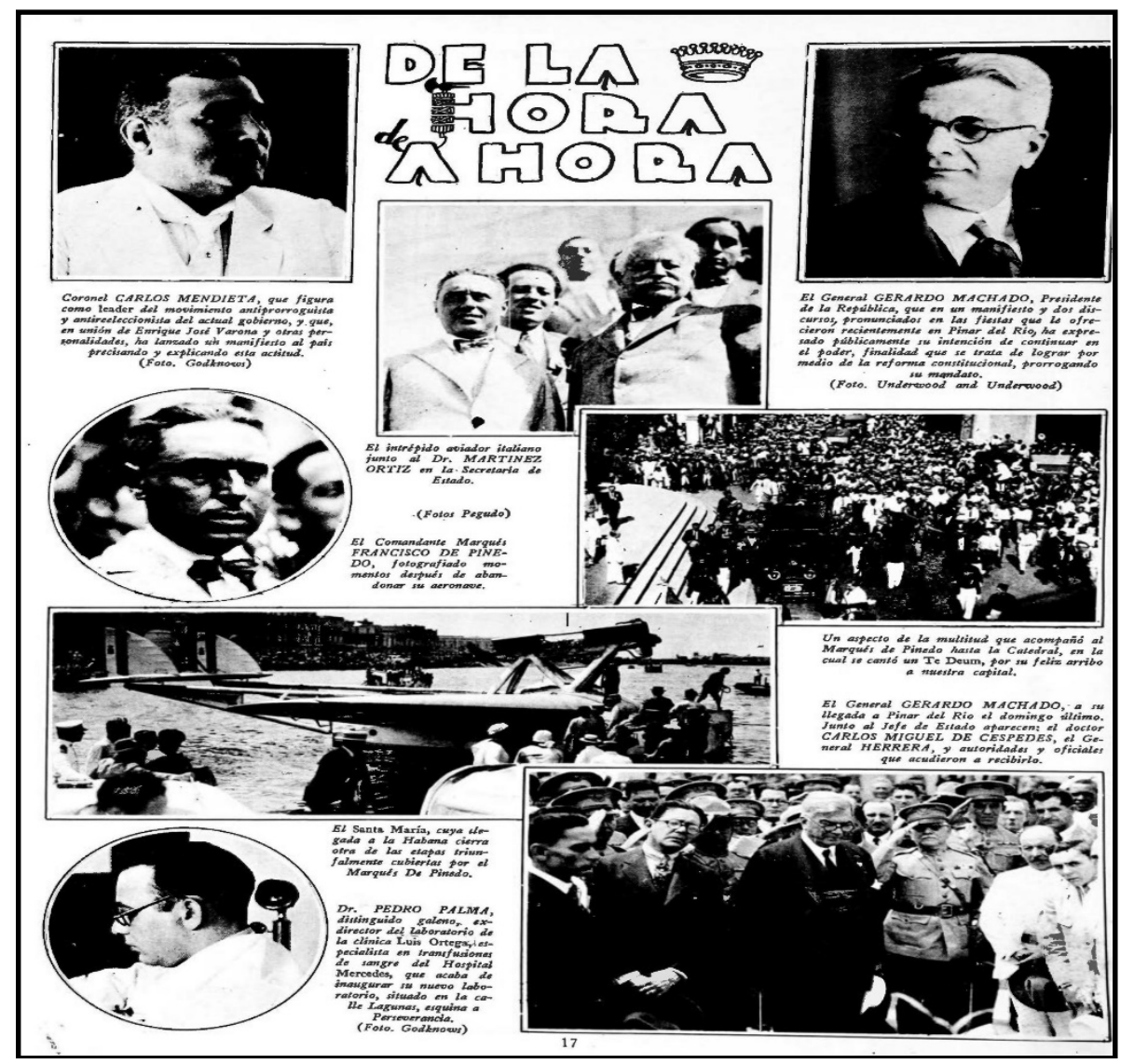

Fig. 2: Imágenes del recibiendo al aviador italiano Francesco de Pinedo. Fuente: Revista Carteles, La Habana, 3 de abril ,1927, p. 17. Biblioteca Nacional de Cuba "José Martí".

Más allá de las particularidades de este incidente, el hecho corrobora la presencia de una célula fascista ( $f a s c l$ ) en La Habana desde la segunda mitad de los años 1920. Asimismo, tanto la presencia de la organización fascista en Cuba, unido a la visita del Italia y la parada de Pinedo, demuestran la importancia que desde muy temprano adquirió el país caribeño en el proceso de acercamiento que diseñó Italia para con Latinoamérica. Sin embargo, como sí sucedió con otros países de la región, donde la necesidad de recursos naturales vitales, o la presencia de una importante comunidad de inmigrantes italianos se convirtieron en los móviles del acercamiento entre Italia y esos países, en el caso de Cuba será su posición geográfica y su cercanía política y económica con los Estados Unidos los dos elementos que convirtieron al país caribeño, durante más de dos décadas, en un punto estratégico para el proceso de propaganda y difusión que trazó el fascismo, tanto para la isla como para el área.

18 GONZÁLEZ, Froilán y CUPULL, Adys. Julio Antonio Mella... Op. cit., p. 75. 
Tal es así que La Habana se convirtió en 1928 en la sede del VII Congreso de la Prensa Latina ${ }^{19}$ a donde asistieron representantes de los diarios más importantes de América Latina y el mundo ${ }^{20}$. Además de abordar los temas candentes de la profesión por aquellos años, el concepto y la pertenencia a la latinidad como elemento cultural que unía a los pueblos latinoamericanos, fue uno de los aspectos que más se destacó en todas las intervenciones. Presidido por el propio presidente de Cuba, Gerardo Machado, la apertura del congreso se dio en La Habana el 7 de marzo y desde el discurso inaugural ofrecido por el director del Diario de La Marina, quien estaba al frente de la comisión organizadora por la parte cubana, se destacaron las virtudes de la raza latina, ideas y pensamientos que estaban en total correspondencia con la política ideológica-cultural de Italia para con América Latina ${ }^{21}$.

\footnotetext{
19 Era la primera vez, desde 1923, que se celebraba el congreso fuera de Europa, y La Habana había sido escogida como sede para ello. Las ciudades anteriores que habían acogido al congreso fueron: Lyon (1923), Lisboa (1924), Roma (1925), Lieja (1926), Madrid (1927) y Bucarest (1927). BATTEMBERG, Domingo. Cuba en 1928: reminiscencias, documentos, informaciones, gráficos, artículos y opiniones del VII Congreso de la Prensa Latina. París: Universite Paris 3, 1928, p. 7.

${ }_{20}$ Aunque hubo una participación variada de representantes de disímiles tendencias ideológicas y temáticas, lo cierto es que participaron delegados de los principales periódicos italianos que, después de 1924, se habían convertido en referentes informativos para los pares latinoamericanos que comulgaban ideológicamente con el fascismo. Los casos más representativos de los rotativos italianos representados fueron: Giornale de Italia, Gazzetta di Popolo, Popolo di Italia, y en el caso de los latinoamericanos, Diario de La Marina (Cuba), Gazzette de Sao Paulo (Brasil), La Época, La Prensa, y La Razón (Argentina). BATTEMBERG, Domingo. Cuba en 1928... Op. cit., p. 28.

${ }^{21}$ Según José I. Rivero, “(...) La latinidad es una condición peculiar del espíritu, una actitud frente a la vida y la manera de reaccionar contra los objetos que nos rodean, común a nuestros pueblos. Ser latino es amar la luz; amar la luz es poseer la gracia, enemiga de las tinieblas; poseer gracia es vivir la vida a pleno sol. No es un vocablo el de la latinidad vacío de sentido. Un francés, un español, un italiano o cualquiera de cuantos pueblan nuestro continente, desde Río Grande a la Patagonia, ante un hecho determinado reaccionaremos, pese a la diferencia de idiomas, si no de idéntico modo, sí tan distinto de como reaccionaria un eslavo o un sajón que puede decirse que la actitud adoptada será, poco más o menos, la misma (...)". El Orden. Diario de la Mañana, Santa Fé, Argentina, 9 de marzo, 1928 , p. 1.
} 


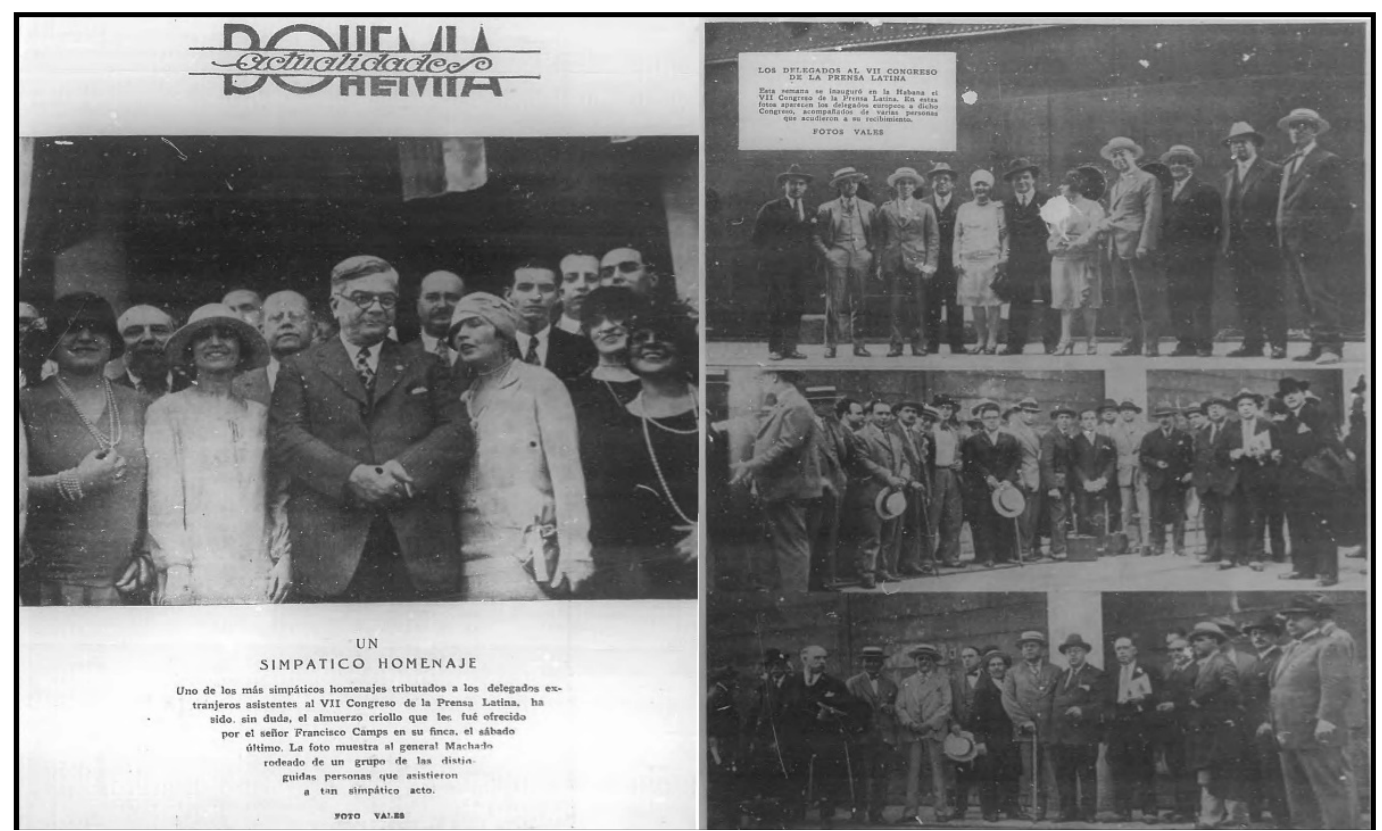

Fig. 3: De izquierda a derecha, Gerardo Machado, junto a delegados en la inauguración del Congreso de la Prensa Latina, 1928, y delegados en su arribo al puerto de La Habana. Fuente: Revista Bohemia, La Habana, 18 de marzo, 1928, p. 27. Biblioteca Nacional de Cuba "José Martí".

Las manifestaciones de apoyo al fascismo por parte de los organizadores nacionales -periodistas en su mayoría-, unido a la participación directa del ministro de Italia en Cuba en la preparación del evento ${ }^{22}$, advierten las conexiones que hubo entre la celebración del evento y la política exterior italiana para con Cuba y la región, además de que un intercambio de mensajes entre la comisión organizadora y el propio primer ministro italiano así lo confirman. A través de la sede diplomática en Cuba, Domingo Battemberg, a nombre de la comisión organizadora, le envió a Mussolini un cable en el que decía:

"Comisión organizadora representada por mí almuerzo íntimo ministro Italia, colonia y periodistas italianos, brinda por Vuestra Excelencia e Italia hija primogénita Roma. - BATTEMBERG"²3.

En respuesta, Mussolini, el 11 de marzo de 1928, respondió el cable expresando lo siguiente:

"Roma, 11 de marzo de 1928- Sírvase Su Señoría hacerse intérprete cerca de la Comisión organizadora del VII Congreso de la Prensa Latina de mi vivo agradecimiento por las amables frases que acaba de telegrafiarme y por el pensamiento dirigido hacia Italia y Roma. Que el nombre y el espíritu de Roma, imperecedero centro de latinidad, animen las labores del Congreso al que envío mis más fervorosos augurios. MUSSOLINl"24.

Teniendo en cuenta el peso de las comunidades italianas de otros países, es

22 El ministro de Italia ofreció, para los congresistas, uno de los dos grandes banquetes que se dieron en La Habana durante el evento. El Orden. Diario de la Mañana, Santa Fé, Argentina, 8 de marzo, 1928 , p. 1.

${ }^{23}$ BATTEMBERG, Domingo. Cuba en 1928... Op. cit., p. 49.

24 Ibídem, p. 49. 
importante destacar la importancia geopolítica y geoestratégica que fue adquiriendo Cuba para el esquema de influencia fascista que proyectó Italia en el área. Según los resultados arrojados por un estudio que hiciera el Dr. Emilio Núñez Portuondo, profesor de Derecho Civil y Derecho Público de la Universidad de La Habana, a solicitud del embajador italiano en la capital, Sr. Nicola Macario ${ }^{25}$, la situación geográfica de Cuba era vital para cualquier labor de propaganda escrita y oral que pensase hacer el gobierno de Italia respecto a América ${ }^{26}$. Precisamente, durante la década de 1930 las intenciones de acercamiento de Italia para con Cuba continuaron a un mismo ritmo. Fue un período que se caracterizó por mantener relaciones diplomáticas cordiales, además de consolidar y reafirmar los históricos vínculos económicos, exceptuando el lapso en que se aplicaron sanciones económicas a Italia por parte de los Estados miembros de la Liga de las Naciones ${ }^{27}$. La decisión del organismo internacional creó un distanciamiento entre ambos países ya que Cuba, como miembro, aplicó la ley, situación esta que no volvió a repetirse hasta la ruptura total de las relaciones en 1941.

El 16 de octubre de 1935 el gobierno cubano publicó en la Gaceta Oficial el decreto 2487 por el cual, como miembro de la Sociedad de Naciones, enumeraba los artículos y/o productos que no se comercializarían con el Reino de Italia hasta tanto no se levantaran las sanciones, y puso en marcha un número de disposiciones que tenían como objetivo, exclusivamente, cumplir con las normas internacionales ${ }^{28}$. Aunque las medidas trajeron un fuerte descontento por parte de la comunidad italiana cercana al fascismo ${ }^{29}$, ya que la aplicación del decreto suponía el reconocimiento a Italia como "país agresor", lo cierto es que el tiempo que duraron las sanciones, así como los productos y las acciones comerciales específicas que se enumeraron, aparentemente no trajeron afectaciones para las relaciones comerciales entre ambos países. No obstante, tomando como referencia los valores de las importaciones y las exportaciones de Cuba durante los años 1935 y 1936, se puede apreciar que Europa era la segunda área comercial más importante para la economía isleña, y dentro de ella, Italia ocupaba el tercer puesto en la lista de los 30 países que activamente comerciaban con Cuba, sólo superado por Alemania y Reino Unido. Precisamente, la misma fuente arroja que las importaciones de productos italianos durante el año 1935 fueron de 887,490 pesos cubanos mientras que las

\footnotetext{
25 Nicola Macario estuvo como ministro plenipotenciario del Reino de Italia en Cuba desde 1934 a 1937. Anuario Diplomático y Consular de la República de Cuba (VII). Habana: Cultural S.A, 1940, p. 470.

${ }^{26}$ GONZÁLEZ, Froilán y CUPULL, Adys. Julio Antonio Mella... Op. cit., p. 182.

27 CONSUEGRA SANFIEL, Alberto. Inglaterra, Francia y la Sociedad de Naciones: intereses y actitudes frente al segundo conflicto ítalo-etíope (1935-1936). Contra Relatos desde el Sur. Dic. 2015, año XI, n. 12, pp. 79-95.

${ }^{28}$ Boletín Oficial de la Secretaría de Estado. La Habana, año XXXIII, octubre, 1935, pp. 457-501. Además de dicho decreto, se emitieron otros respecto a las sanciones a Italia, como por ejemplo el decreto 2657, firmado el 31 de octubre de 1935, referido a limitar las transacciones financieras con el gobierno italiano con Cuba, o el decreto 2890, mediante el cual se ampliaba la lista de artículos y el material de guerra que se prohibía comerciar con Italia, el cual salió publicado en la Gaceta Oficial el 12 de diciembre de 1935. Boletín Oficial de la Secretaría de Estado. La Habana, año XXXIII, octubre, 1935, pp. 497-501.

${ }^{29}$ La aplicación de la medida trajo un fuerte descontento que se expresó a través de la prensa, en especial en el Diario de La Marina, vocero por excelencia del fasci y de la comunidad italiana en La Habana.
} 
exportaciones de productos cubanos hacia Italia fueron de 65,647 pesos cubanos $^{30}$. Sin embargo, durante el año 1936 estas cifras mermaron considerablemente, reduciéndose a cero las importaciones, mientras que las exportaciones solo fueron de 3,639 pesos cubanos ${ }^{31}$.

No hay duda que dichas medidas sí afectaron, aunque de manera coyuntural, el intercambio comercial entre ambos países, así como el desempeño de algunas compañías italianas que, con sede en Roma, operaban directamente en Cuba y en Estados Unidos, en especial, aquellas dedicadas al transporte marítimo de pasajeros. Y es que desde finales de la década de 1920 compañías navieras italianas desembarcaron en Cuba con el objetivo de brindar sus servicios de transporte a destinos como Nueva York y Europa. Durante toda la década de 1930, por ejemplo, la compañía Italian Line se convirtió en una de las empresas de transporte de pasajeros más importante del país. Con su oficina principal en la calle Empedrado nro.4, en La Habana, la compañía promocionaba sus servicios en el Diario de La Marina e instaba a los lectores a viajar a Europa vía Nueva York, detallando a quienes elegirían los servicios de la compañía cómo podría ser el viaje a Italia, las grandezas y los avances que había logrado el país, así como las distintas paradas -Nueva York, Lisboa, Gibraltar, y en Italia, Roma, Nápoles, Nisa, Génovaque tenían en su trayecto hasta llegar a Italia, lo que también servía para aquellos que deseaban viajar a cualquiera de esas ciudades sin llegar a Italia ${ }^{32}$.

Una vez levantada las sanciones en julio de 1936, las relaciones entre ambos países conservaron su ritmo habitual e Italia continúo cultivando sus intenciones de acercamiento al país caribeño a partir de la organización de actividades culturales que, si bien tenían claros objetivos políticos, fueron siempre divulgadas y reconocidas, hasta por el propio gobierno cubano como parte de la promoción cultural que se le hacía a Italia en el exterior ${ }^{33}$. Así, durante este período, encontramos varios ejemplos que muestran cómo la glorificación del pasado romano se convirtió en la columna vertebral del discurso y las intenciones de todos los que de alguna forma u otra, ya fueran diplomáticos o periodistas cubanos que habitualmente escribieron en los diarios, buscaban convencer a la sociedad de la necesidad de apoyar a Italia en cada una de las acciones expansivas que llevó adelante, en especial, la invasión a Etiopía, o simplemente presentar los logros de Mussolini y del fascismo como una alternativa posible a seguir.

\section{De la consolidación a la ruptura de los vínculos}

La llegada a Cuba del nuevo representante diplomático, Giovanni Persico, en agosto de 1937, significó un cambio importante en las relaciones entre Cuba e Italia,

30 Boletín Oficial de la Secretaría de Estado. La Habana, año XXXIII, (abril, mayo, junio), 1936, p. 104. El peso cubano tenía una paridad con el dólar estadounidense de 1 USD = 1 peso cubano.

${ }^{31}$ Boletín Oficial de la Secretaría de Estado. La Habana, año XXXIV, (enero, febrero, marzo), 1937, p. 108.

32 Diario de La Marina, La Habana, 19 de agosto, 1937, p. 3. Este tipo de anuncios se repetirán durante casi toda la década de 1930 en el diario.

${ }^{33}$ Durante los años de 1935 a 1941, casi todas las actividades culturales que fueron organizadas por la Legación de Italia en La Habana, aparecieron promocionadas en el Boletín Oficial de la Secretaría de Estado. 
dinamizando las labores proselitistas que habitualmente llevaban a cabo las instituciones culturales italianas en La Habana ${ }^{34}$.

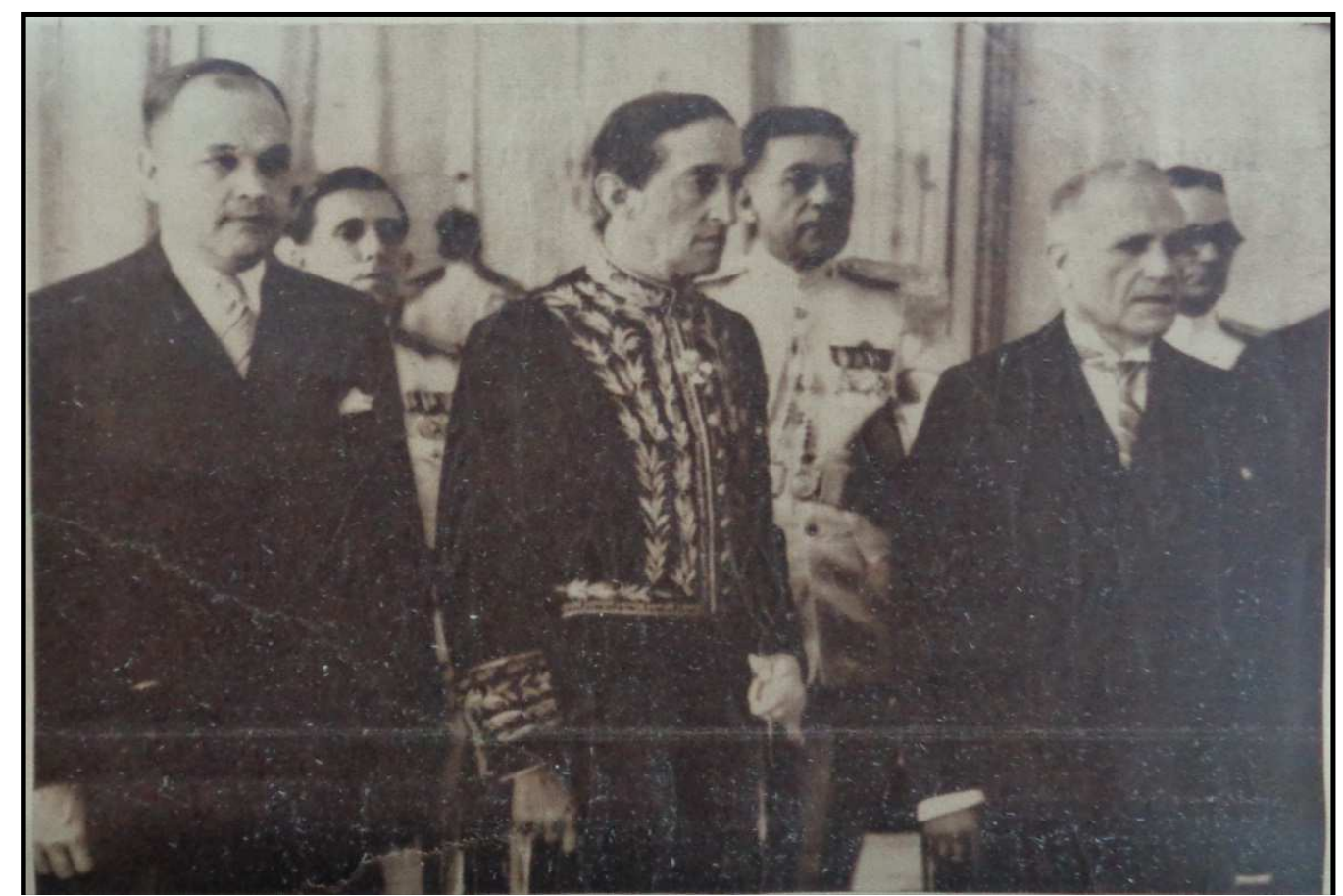

Fig. 4: Momento de la entrega de cartas credenciales del ministro Giovani Persico. Fuente: Diario de La Marina, La Habana, 19 de agosto, 1937, p. 2. Biblioteca Nacional de Cuba "José Martí".

A pocos meses de haber llegado, el nuevo embajador informó a la Secretaría de Estado la creación por parte del gobierno de Roma de un premio exclusivo para Cuba con el fin de premiar al mejor libro de autor cubano ${ }^{35}$. El premio Roma, como se le nombró, aclaraba en la reglamentación que dicho reconocimiento "(...) se había instituido por parte del Gobernador de Roma con el fin de estrechar aún más los lazos de amistad que unían a Cuba, además de que los autores debían inspirarse para la realización de sus obras en la universalidad de Roma en cuanto a su concepción y desarrollo, así como la maravillosa y decisiva influencia que la Antigua Roma ejerció a través de los siglos, sobre las múltiples manifestaciones del pensamiento humano (...)"36.

Aunque no se conoce si se llegó a premiar a algún escritor cubano, el reglamento también fijaba el día, el jurado y el lugar a donde se debían remitir los 5 ejemplares de la obra que participaría del certamen. En este caso, se escogió el 21 de abril como el día en que se darían los resultados del concurso -con motivo del aniversario de la fundación de la ciudad de Roma-, el ministro de Italia en Cuba encabezaría el jurado, y los resultados serían expuestos en la sede de la Legación de Italia en La Habana. Además, el Dr. Paolo Nicolai, director de los cursos de Cultura Italiana en la Casa de Italia, la cual se encontraba en la calle Paseo de Martí

\footnotetext{
34 Diario de La Marina, La Habana, 19 de agosto, 1937, p. 2.

${ }^{35}$ Boletín Oficial de la Secretaría de Estado. La Habana, año XXXIV, agosto, 1937, p. 169.

36 Boletín Oficial de la Secretaría de Estado. La Habana, año XXXIV, septiembre, 1937, p. 289.
} 
nro. 44, en la capital cubana, sería el encargado de asesorar a los interesados ${ }^{37}$.

Del mismo modo, en consonancia con la creación del Instituto Internacional de Cinematografía Educativa en Italia, fundación que también fue comunicada y presentada a las autoridades cubanas como un logro del régimen fascista mediante el cable 621 de diciembre de $1937^{38}$, y como parte de la infraestructura que crearon las instituciones culturales pro-fascistas con el fin de ganar adeptos y apoyo al interior de la exigua comunidad italiana en Cuba, el nuevo embajador inauguró el 9 de marzo de 1938 una nueva sala de espectáculos de la Sociedad Italiana de Asistencia ${ }^{39}$. Con la presencia de importantes personalidades y dirigentes de la Casa de Italia, como el ya mencionado Dr. Paolo Nicolai, el diplomático italiano pronunció una conferencia titulada "Carácteres y misión del teatro en la Nueva Italia", ratificando la importancia que tenía para el país que representaba el enaltecimiento y recuperación de la admiración a la cultura italiana en el exterior ${ }^{40}$.

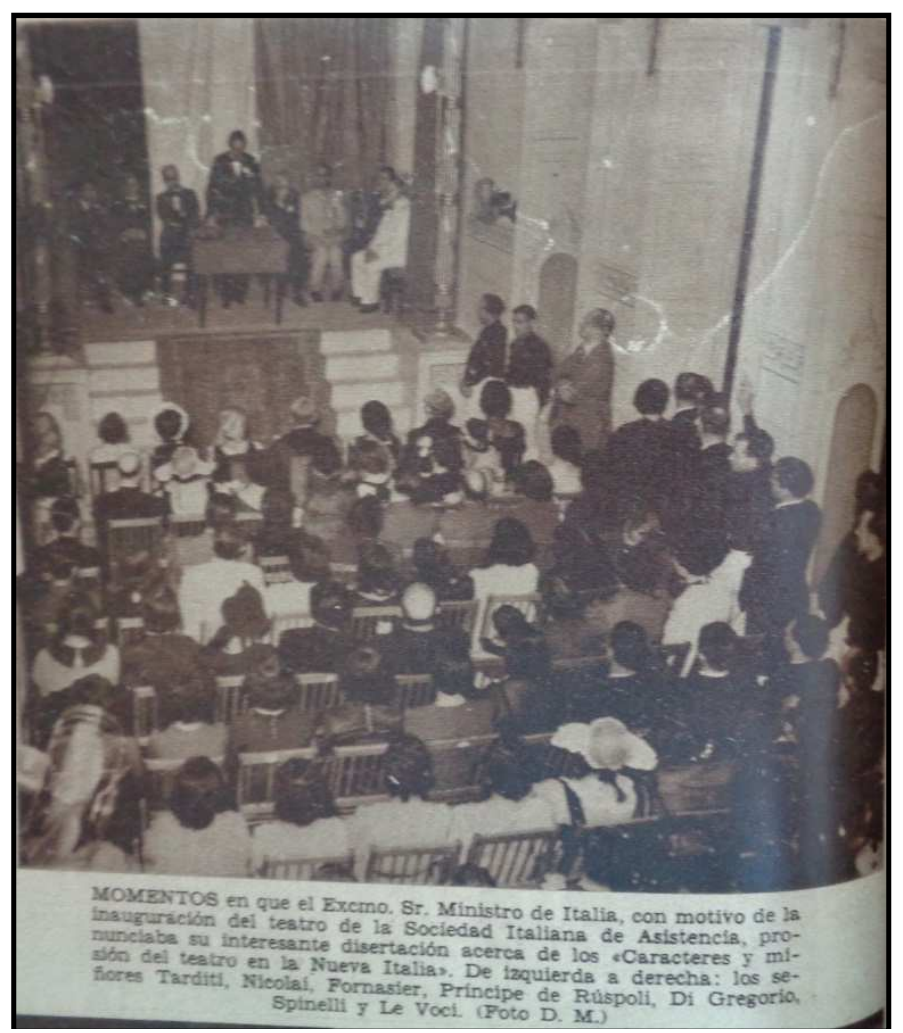

Fig. 5: Conferencia del embajador de Italia, Giovani Persico, cuando inauguraba el teatro de la Sociedad Italiana de Asistencia. Fuente: Diario de La Marina, La Habana, 9 de marzo, 1938, p. 29. Biblioteca Nacional de Cuba "José Marti".

El estudio del idioma italiano fue otros de los aspectos prioritarios de la agenda cultural de los representantes italianos en La Habana. Bajo la tutela de la Casa de Italia y en estrecha coordinación con la embajada, el Instituto "Vittorio Emmanuele" tenía como tarea fundamental la promoción de la enseñanza de la lengua para así

\footnotetext{
37 lbídem, p. 289.

${ }^{38}$ Boletín Oficial de la Secretaría de Estado. La Habana, año XXXIV, diciembre, 1937, p. 675.

39 Diario de La Marina, La Habana, 9 de marzo, 1938, p. 29.

40 lbídem, p. 29.
} 
lograr el acercamiento a la cultura mediante la lectura y comprensión de los textos, tanto de aquellos que producía el propio Ministerio de Relaciones Exteriores, o simplemente la literatura clásica que llegaba desde Roma. Los alumnos, la mayoría descendientes de la comunidad italiana o provenientes de la alta burguesía habanera, se convirtieron durante la segunda mitad de la década del 30 en el centro de las actividades artísticas y culturales relacionadas con el idioma. Eran ellos, en palabras de los oradores que disertaban durante las ceremonias de apertura o cierre de los cursos de idioma, los fieles inspiradores de la cultura y la lengua italiana en América ${ }^{41}$. En varios momentos, también, la institución agasajó a escritores destacados que contribuían con su trabajo a consolidar los vínculos culturales entre Cuba e Italia, a través de la publicación de pequeñas obras literarias de temáticas caribeña pero en idioma italiano. Tal es el caso del homenaje que se le hizo a la escritora ítalo-cubana Alba de Céspedes quién, además de pertenecer a una de la familia de más importantes de la política y la cultura de $\mathrm{Cuba}^{42}$, desde el principio de la década de 1930 había comenzado a publicar cuentos y novelas en los principales diarios y revistas de Italia, convirtiéndose para las autoridades italianas en el ejemplo perfecto de unión cultural entre el país caribeño y la cultura italiana ${ }^{43}$.

${ }^{41}$ Diario de La Marina, La Habana, 22 de marzo, 1939, p. 11.

42 Alba de Céspedes era hija de Carlos Manuel de Céspedes y Quesada (embajador cubano en Italia, representante a la Cámara, Secretario de Estado del presidente Alfredo Zayas y más tarde presidente provisional en 1933), y su mujer italiana, Laura Bertini y Alessandri. Su abuelo fue Carlos Manuel de Céspedes, una de las grandes figuras en la Guerra de los Diez Años, y prima de Pedro Figueredo, el autor del Himno Nacional cubano. Contradictoriamente, durante los años de las Segunda Guerra Mundial, Alba de Céspedes luchó en contra del régimen fascista italiano, llegando a sufrir encarcelamiento por esto. Ecured. Alba de Céspedes [en línea]. [Consulta: 30-04-2018] Disponible en <https://www.ecured.cu/Alba de_C\%C3\%A9spedes>. NAVARRETE, Williams. El enigma de una ítalocubana en París. El Nuevo Herald [en línea]. 2016. [Consulta: 30-04-2018]. Disponible en

$<$ http://www.elnuevoherald.com/vivir-mejor/artes-letras/article91362537.html>.

${ }^{43}$ En esta actividad cultural, y en otras que se dieron antes, eran común que se hicieran presentes personalidades de la cultura y de la política de Cuba, dando muestras de las buenas relaciones que había entre ambos países, además de la aceptación por el gobierno de Cuba de la política cultural que mantenían las autoridades diplomáticas y la comunidad italiana. En este caso, estuvo presente el director de Cultura, de la Secretaría de Educación, el intelectual habanero José María Chacón y Calvo, quién fuera uno de los exponentes más importantes del movimiento nacionalista y cultural que se diera en Cuba en la década de 1930. Diario de La Marina, La Habana, 22 de marzo, 1939, p. 11. 


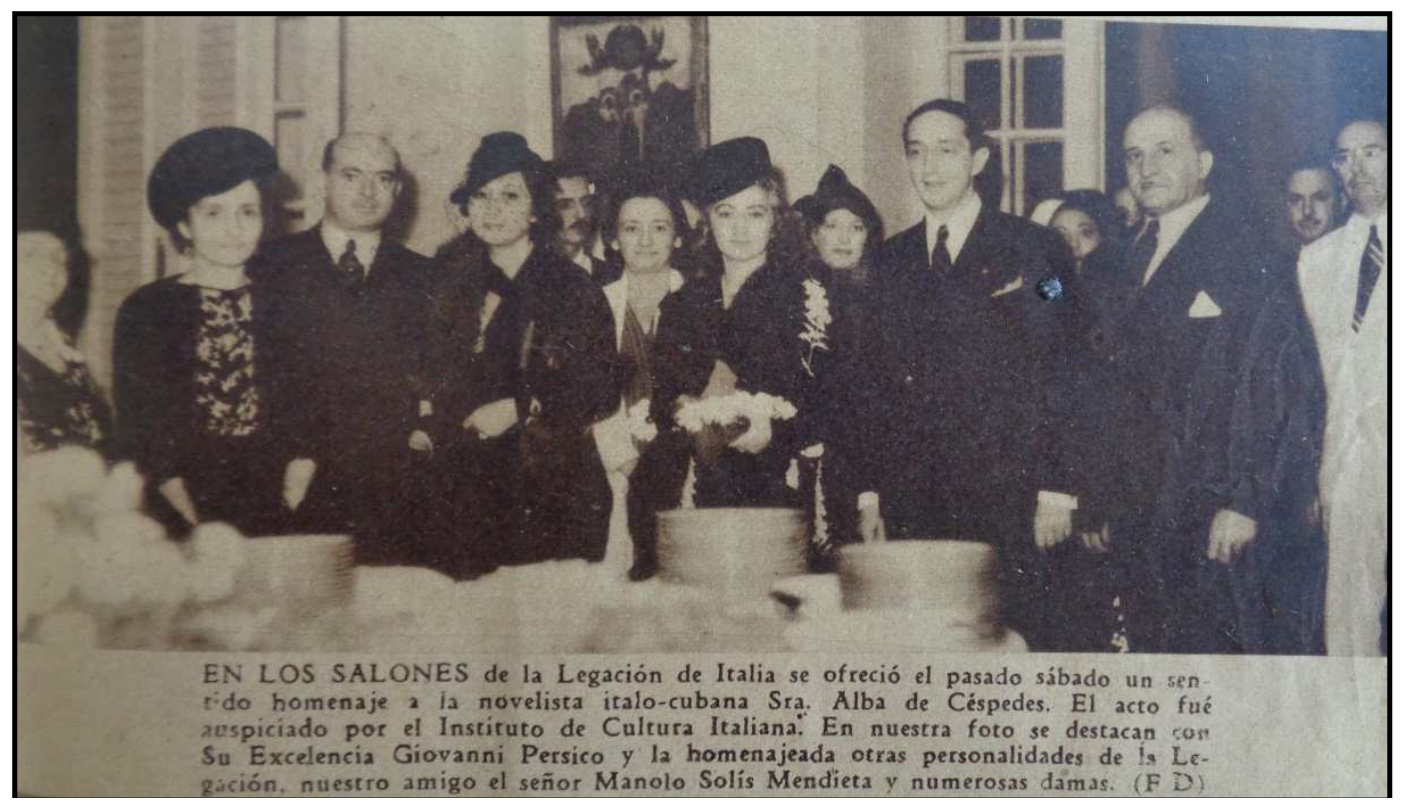

Fig. 6: Homenaje a la novelista Alba de Céspedes. Fuente: Diario de La Marina, La Habana, 21 de marzo, 1939, p.29. Biblioteca Nacional de Cuba "José Martí".

A partir de 1935 y hasta casi principios de 1939, también, se le dio espacio en la programación radial cubana a emisiones de Italia, especialmente en días y fechas conmemorativas en la que se dirigían al pueblo las personalidades políticas más importantes del país, como Mussolini o el propio Rey Víctor Manuel III. Además de poner al aire las alocuciones, los programas radiales, los cuales se transmitían en español e italiano, completaban con la transmisión de un programa cultural que incluía, por ejemplo, la orquesta de voces y coro perteneciente al teatro Scala de Milán, además de que se podían oír las campanadas de la Catedral de San Pedro, en Roma ${ }^{44}$.

A nivel oficial, el propio Giovanni Persico se encargó de hacer llegar a las más altas autoridades cubanas los nuevos cambios y logros que iba alcanzado el gobierno fascista. Como mismo sucedió con la fundación del Instituto de Cinematografía, o con el premio Roma, -fue el propio diplomático a nombre de la Legación de Italia quien informó a la Secretaría de Estado dichas novedades-, el representante diplomático tuvo a su cargo la entrega al propio presidente de la República de Cuba, Cor. Federico Laredo Brú, y a nombre de su gobierno, la obra titulada "Los navegantes italianos primeros descubridores de América Latina". Aunque quedó registrado como un gentil obsequio, lo cierto es que la obra constituía una de las tantas publicaciones que editó y publicó el Ministerio de Asuntos Extranjeros de Italia y que, mediante una historia documentada con imágenes y respaldada por un minucioso estudio histórico, exhibía a las sociedades y a los gobiernos latinoamericanos, y en este caso al cubano, el rol destacado que tuvieron los italianos y su cultura, desde Cristóbal Colón hasta Girolando de Verrazano, en el descubrimiento y desarrollo de América ${ }^{45}$.

\footnotetext{
44 También se podían sintonizar directamente algunas estaciones radiales de Roma que se trasmitían en onda corta. Diario de La Marina, La Habana, 12 de marzo, 1939, p. 15.

45 Boletín Oficial de la Secretaría de Estado. La Habana, año XXXV, enero, 1938, p. 85.
} 
Por su parte, en Italia, los representantes diplomáticos cubanos también eran invitados por el gobierno italiano a distintas actividades culturales relacionadas con América con el fin de reforzar los vínculos entre Roma y La Habana. En casi todas las actividades en las que estuvo presente algún representante del cuerpo diplomático cubano, se exaltaron siempre los vínculos entre ambos países, los logros y profundos cambios que en materia de política cultural había alcanzado Italia después de la llegada de Mussolini, y por supuesto, la admiración que sentían los italianos por la cultura cubana y el país en sentido general ${ }^{46} .1938$ fue un año prolífero para las relaciones entre Italia y Cuba. Sin duda, la llegada a La Habana del nuevo embajador Giovanni Persico acarreó un marcado movimiento en el proceso de acercamiento entre ambos países, lo que se tradujo en una mayor visibilización de la comunidad italiana en Cuba que comulgaba con el fascismo ${ }^{47}$, sus actividades político-culturales, al igual que aquellas de carácter oficial que tuvieron como protagonistas los dos países.

Precisamente, será la firma de un nuevo acuerdo comercial entre Italia y Cuba el evento más significativo que se dio en la historia de las relaciones entre ambas naciones durante el período. Con la presencia de importantes figuras de la política y la economía nacional, el 29 de agosto de 1938 ambos países firmaron un protocolo adicional al Tratado de Amistad, Navegación y Comercio que se había firmado entre Italia y Cuba en 1903 con el objetivo de sustituir el artículo $3^{48}$. La reestructuración del tratado, según las propias declaraciones de los signatarios, el Dr. Juan J. Remo, secretario de Estado, y el ministro Giovanni Persico en representación de Italia, suponía la entrada en una nueva fase de las buenas relaciones comerciales existentes entre ambos países, lo que se traduciría en ganancias para las economías de ambas naciones. La firma del protocolo no era más que el resultado

46 Durante el período analizado hay varios ejemplos de eventos y/o exposiciones italianas inauguradas en las que fue invitado el embajador cubano en Italia. Uno de los ejemplos más importantes fue la inauguración de la Galería Nacional de Arte Moderno, en Roma, el 26 de mayo de 1938, a donde asistió el encargado de negocios de Cuba, el Dr. Carlos Tabernilla. En esa ocasión, la invitación estuvo a cargo del propio ministro de la Cultura Popular de Italia, y entre los muchos trabajos que se resaltaron, estuvo la escultura del escultor italiano Vicenzo Gemito titulada "Muchacha cubana". Boletín Oficial de la Secretaría de Estado. La Habana, año XXXV, junio, 1938, p. 639.

47 Además de no existir registros en el Archivo Nacional de Cuba, en la revisión de la prensa que se hizo con motivo de esta investigación, no aparecieron ninguna manifestación por parte de integrantes de la comunidad italiana en Cuba que condenaran al fascismo y/o crearan alguna asociación paralela a las ya mencionadas. En tal sentido, todo indicaría que al haber pocos inmigrantes italianos, la mayoría de ellos asentados en La Habana, así como la eficaz labor de asistencia y desarrollo de actividades culturales que llevaron las autoridades diplomáticas en Cuba, la inmensa mayoría de los inmigrantes participaron de las actividades programadas por la Casa de Italia, la misma que formaban parte del andamiaje político fascista, aún cuando los participantes no comprendieran en su totalidad el alcance y la implicancia de esas acciones, como sucedió en otros países latinoamericanos, como Uruguay y México, por ejemplo.

${ }^{48}$ La firma del Tratado de Amistad, Navegación y Comercio de 1903 fue el primer tratado firmado por Cuba por una nación no americana después de la fundación de la República. Hasta 1938 solamente se habían firmado con Italia, de manera oficial, 4 tratados y/o convenios: el Tratado de Amistad, Navegación y Comercio (1903), Convenio de Extradición entre Italia y Cuba (1928), Cambios en el artículo 4 del Convenio de Extradición entre Italia y Cuba (1932), y protocolo adicional al Tratado de Amistad, Navegación y Comercio de 1903 (1938). Todos fueron publicados en las respectivas gacetas oficiales de ambos países. 
de las buenas intenciones de ambos gobiernos de sustituir las antiguas normas que regulaban el comercio por otras a tono con las realidades del momento ${ }^{49}$.

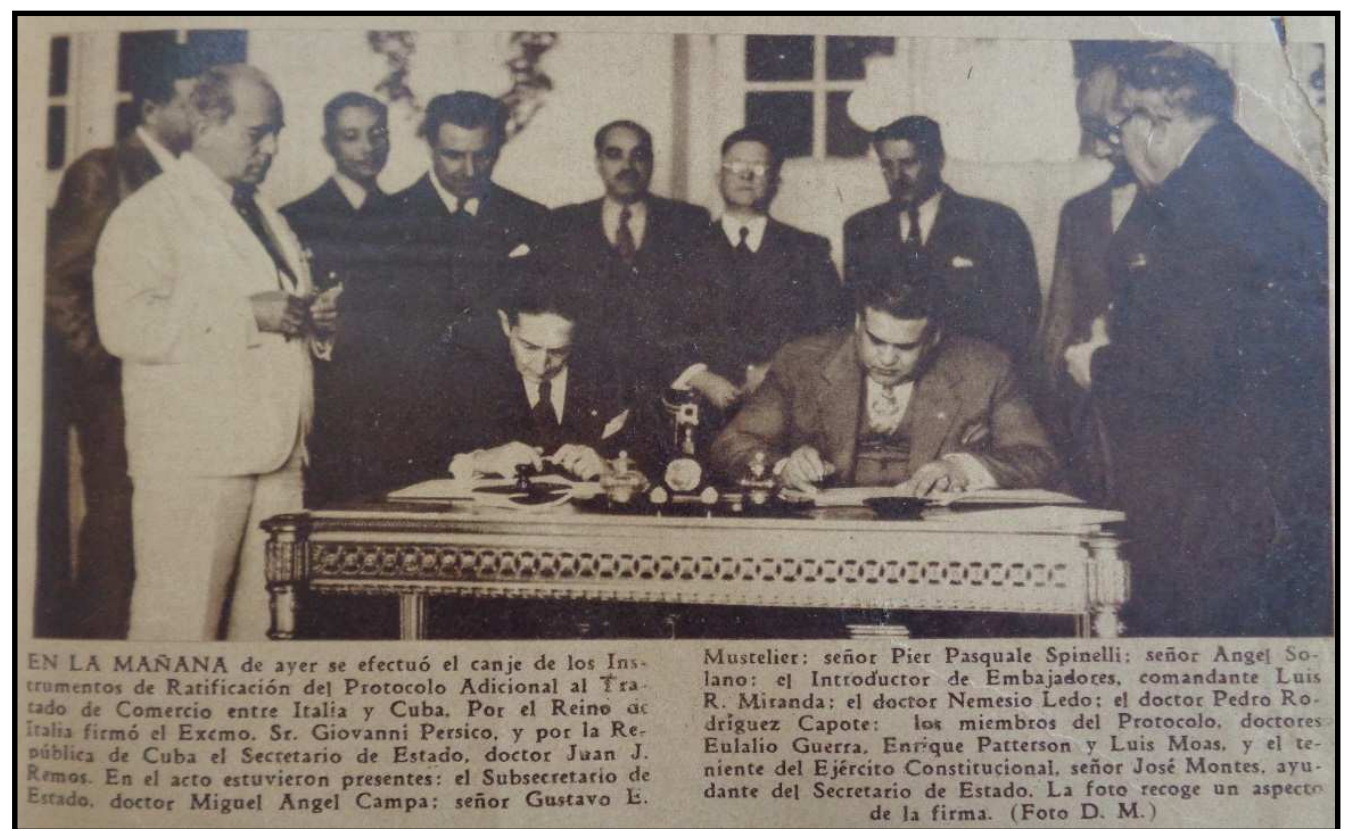

Fig. 7: Firma del protocolo adicional al Tratado de Amistad, Navegación y Comercio. Fuente: Diario de La Marina, La Habana, 21 de marzo, 1939, p. 29. Biblioteca Nacional de Cuba "José Martí".

Sin embargo, contradictoriamente, a partir de la firma del acuerdo comercial con Italia se inició un lento pero visible proceso de cambio de actitud de Cuba frente a aquellos países, dígase Italia y Alemania, que a la altura de 1938 eran vistos como responsables de la inestabilidad y del deterioro del orden internacional. Si hasta el momento el país había mantenido una posición de respeto ante lo que sucedía en Europa, a partir de la fecha se puede observar un gobierno cubano que, siempre cumpliendo las normas de la política exterior, dio cuenta de que seguía con atención el progresivo deterioro de la paz europea y mundial, además de su alineación con la

49 Puntualmente el protocolo adicional modificaba el artículo 3 por el cual se le había otorgado el beneficio de "nación más favorecida" a Italia, mientras que ahora, en función de los cambios que se le había hecho al arancel de aduana de Cuba en 1935, se establecía principalmente lo siguiente:

1) La tarifa mínima en los aranceles a los artículos importados en Cuba que, originarios del suelo o de la industria de aquellos países que, anualmente, adquiriesen directamente de Cuba y en artículos originarios de su suelo o industria, por un valor equivalente, al menos, a la mitad del valor de los que Cuba importaba de Italia.

2) Las dos naciones se concedían recíprocamente el tratamiento de nación más favorecida.

3) Para que los productos procedentes de Italia gozaran en Cuba de tratamiento aduanal concedido a la nación más favorecida, la importación de productos cubanos en Italia se tenía que mantener a nivel inferior a la mitad del valor de las importaciones de productos italianos en Cuba.

4) Cuba obtenía el inmediato pago de sus mercancías sin demoras de las correspondientes divisas, y de sus ventas mínimas anuales consistirían en determinados contingentes de productos anuales (café, cacao, miel de caña, pieles, tabaco en rama y manufacturado).

5) Se fijaba para el primer año del convenio la compra de estos productos por un total de 6 millones de liras o su equivalente en dólares, y para los años sucesivos, en el 50 por ciento del valor de las importaciones anuales que Cuba efectuara a Italia. Firmado el Protocolo Adicional al Tratado con Italia. Boletín Oficial de la Secretaría de Estado. La Habana, año XXXV, agosto, 1938, p. 123. 


\section{política norteamericana respecto a países como Italia y Alemania ${ }^{50}$.}

Una vez que las tropas alemanas cruzaron las fronteras de Polonia y se dio por iniciada la Segunda Guerra Mundial, el presidente de Cuba, Cnel. Federico Laredo Bru, publicó una proclama en la que, además de hacer mención a la situación hostil que vivía Europa e informar al pueblo de la situación, esclareció la postura del país de respeto a las normas internacionales establecidas tras el fin de la Primera Guerra Mundial y declaró el "estado de neutralidad" de acuerdo a los principios generales del derecho internacional ${ }^{51}$. Dicha proclama, a las horas, se convirtió en el decreto presidencial nro. 2073/1939 por el cual se ratificaba la neutralidad de Cuba, además de que se establecían medidas puntuales para aplicar respecto a los países beligerantes. El decreto hizo especial énfasis en aquellas intrucciones destinadas a la prohibición de todo tipo de actividad radiotelegráficas y radiotelefónicas en el territorio nacional, así como la regulación de entrada y salida de barcos a puertos cubanos, ya sean mercantes o de guerra ${ }^{52}$.

La aplicación de las medidas estaban orientadas a dejar en claro la desaprobación del gobierno de Cuba a que el territorio nacional sirviese de base a extranjeros y/o nacionales para la organización y promoción de actividades a favor de algún país en guerra ${ }^{53}$. Unido a esto, el compromiso de Cuba en la defensa de la neutralidad y de la paz, el cual fue expresado en las respectivas reuniones que se dieron entre los representantes de los distintos países latinoamericanos para abordar el tema de la guerra en Europa ${ }^{54}$, se convirtieron en barreras infranqueables

\footnotetext{
50 Durante el período estudiado, las relaciones entre Cuba y Alemania fueron cordiales, casi al mismo nivel que con Italia. Económicamente, Alemania era uno de los países que más comercio tenía con Cuba, y a nivel diplomático, Alemania cursó invitaciones importantes al gobierno de Cuba con el objetivo de que participara en eventos culturales y políticos a celebrarse tanto en Cuba como en Berlín. Por su parte, los distintos gobiernos cubanos respondieron positivamente a esas invitaciones. Algunos ejemplos son: invitación al Congreso Internacional Municipal (1936); envío por parte del gobierno de Cuba un busto de José Martí al Instituto Iberoamericano de Berlín, el cual se develó en 1937; el Estado cubano promocionó la creación de la "Orden de Mérito del Águila Alemana", en 1937, para honrar a ciudadanos extranjeros que se hagan acreedores del Reich alemán; reconocimiento por parte de Cuba de Austria y Alemania como una sola unidad comercial (1938); reconocimiento de las nuevas fronteras entre Alemania y Checoslovaquia al considerar alemanas las mercancías procedentes del Sudeten (1939). Boletín Oficial de la Secretaría de Estado. La Habana (1935-1939).

51 Boletín Oficial de la Secretaría de Estado. La Habana, año XXXVI, julio-agosto-septiembre, 1939, p. 12.

52 Boletín Oficial de la Secretaría de Estado. La Habana, Año XXXVI, julio-agosto-septiembre, 1939, pp. 12-15.

${ }^{53} \mathrm{~A}$ raíz del comienzo de la guerra, la Secretaría de Gobernación envió a los jefes de las divisiones de la Policía Nacional, la relación detallada de los nacionales de Inglaterra, Francia, Polonia y Alemania -países que habían entrado en la guerra-, que estaban radicados en territorio nacional, con el objetivo de que fueran vigilados. Esta medida, según Gobernación, respondía al "estado de neutralidad" de Cuba. Diario de La Marina, La Habana, 13 de septiembre, 1939, p. 2.

54 Una vez que se desató la guerra, los gobiernos de Argentina, Brasil, Chile, Colombia, Estados Unidos, México, Panamá, Perú y Cuba, considerando que la guerra en Europa se consideraba un hecho susceptible que perjudicaría la paz de América, además de los respectivos convenios firmados acerca del mantenimiento de la paz, tanto en la Conferencia Interamericana de Buenos Aires (1936) así como en Lima (1938), llamaron a una reunión extraordinaria y consultiva de los ministros de Relaciones Exteriores en Panamá, que sesionó del 23 de septiembre al 3 de octubre de 1939 con la participación de los ministros de todos los países antes mencionados, además de Ecuador y El Salvador.
} 
que hicieron que las relaciones Cuba-Italia fueran paulatinamente enfriándose. Respecto a este último aspecto, las declaraciones hechas por la delegación cubana que asistió a la reunión de ministros en Panamá, la cual estuvo presidida por Miguel Angel Campa, secretario de Estado, dio cuenta de la férrea postura que tomaría Cuba frente a aquellos países que, como Alemania e Italia ${ }^{55}$, atentaban contra la paz mundial y la estabilidad del mundo, incluyendo el continente americano ${ }^{56}$.

En consonancia con la actitud del gobierno cubano a partir del deterioro de las relaciones internacionales en Europa, significativamente después de la firma del protocolo comercial entre Italia y Cuba, los diplomáticos italianos, así como las instituciones culturales habaneras que habían trabajado al unísono para respaldar el proyecto político fascista, dejaron de figurar en los medios gráficos y oficiales que habitualmente publicitaban sus actividades. A nivel oficial, aparentemente, la embajada italiana en La Habana estuvo a cargo de diplomáticos de segunda línea primer secretario ${ }^{57}$ - aún cuando oficialmente el embajador asignado seguía siendo Giovanni Persico. No fue hasta 1940, durante los actos oficiales de asunción del nuevo presidente cubano, Cnel. Fulgencio Batista y Zaldívar, que apareció otra vez la Legación de Italia y su embajador dentro del listado del cuerpo diplomático exterior acreditado en $\mathrm{Cuba}^{58}$.

Justo antes de que Italia entrara en la guerra, el gobierno de Cuba dio pasos que, conociendo la historia de las relaciones diplomáticas entre Italia y Cuba, así como los procedimientos que seguía el Ministerio de Relaciones de Cuba para

\footnotetext{
55 Italia había firmado el 22 de mayo de 1939 el Pacto de Acero con Alemania mediante el cual, según su artículo III, "(...) en caso de que uno de los signatarios se viera envuelto en una guerra, el otro le prestaría asistencia inmediata (...)" lo cual prácticamente, una vez Alemania entró en guerra, presagiaba la entrada de Italia a la guerra, como sucedió en 1940. SEARA VÁZQUEZ, Modesto. La paz precaria. De Versalles a Danzig (II). México: Facultad de Ciencias Políticas y Sociales, 1970, pp. 519-521.

56 Miguel Ángel Campa, secretario de Estado, fue uno de los delegados que con más vehemencia e insistencia propuso a las naciones latinoamericanas permanecer neutrales ante el conflicto y reprobar toda acción que tienda a llevar las hostilidades a los mares americanos. La delegación cubana, además, propuso el establecimiento de un sistema de consultas de carácter permanente ante los peligros de la guerra, junto a un Comité Permanente de Neutralidad. Evidentemente, en una conferencia de tamaña envergadura, con la presencia de países de tanto peso como Estados Unidos en las relaciones interamericanas del período, la intervención de Cuba, así como la propuesta denotan el alineamiento de la política diplomática cubana con la estadounidense. Boletín Oficial de la Secretaría de Estado. La Habana, año XXXVI, octubre, 1939, pp. 18-19.

57 Boletín Oficial de la Secretaría de Estado. La Habana, año XXXVI, abril-mayo-junio, 1939, p. 14; Boletín Oficial de la Secretaría de Estado. La Habana, año XXXVII, abril-septiembre, 1940, p. 3.

58 Boletín Oficial de la Secretaría de Estado. La Habana, año XXXVII, octubre-diciembre, 1940, pp. 914. Durante 1939, comunicación entre el embajador estadounidense en Roma y el presidente norteamericano demuestran cómo se fueron deteriorando las relaciones diplomáticas entre Estados Unidos e Italia, situación que se trasladó a las relaciones Cuba- Italia por las estrechas relaciones entre la Casa Blanca y La Habana. Carta de William Phillips a Franklin D. Roossevelt, Rome, Italy, May 26, 1939. Diplomatic Correspondence, Franklin D. Roosevelt Presidential Library \& Museum, Box 42, Italy - Phillips, William, 1935-May 1939 [en línea]. [Consulta: 14-01-2019]. Disponible en $<$ http://www.fdrlibrary.marist.edu/ resources/images/psf/psfa0401.pdf>. Para 1940, el alineamiento entre Estados Unidos y Cuba en la toma de decisiones respecto la guerra era visible dadas las conversaciones contantes que tenía la Cancillería y la Secretaría de Estado de Cuba con el embajador norteamericano respecto a la guerra. Diario de La Marina, La Habana, 20 de junio, 1940, p. 9.
} 
otorgar determinadas condecoraciones, mostraban el inminente rompimiento de las relaciones entre Roma y La Habana. Uno de los gestos fue distinguir con la "Orden Nacional de Mérito Carlos Manuel de Céspedes" a grandes personalidades de la política y la diplomacia italiana ${ }^{59}$, y el otro fue la designación de Orestes Ferrara y Marino como "Enviado Especial" a Europa en función de llevar a cabo gestiones especiales referentes a las relaciones comerciales de Cuba con varias naciones, en especial, con Italia ${ }^{60}$.

En el caso de la entrega de la "Orden Nacional de Mérito Carlos Manuel de Céspedes" a importantes miembros del gobierno fascista -máxima distinción que otorgaba el gobierno de Cuba como recompensa a los servicios prestados por nacionales o extranjeros en el ejercicio de cargos diplomáticos u otros eminentes servicios prestados a Cuba-, vislumbraba el fin de un período ya que históricamente esa distinción, en caso de merecerla, era entregada cuando el diplomático finalizaba su misión. No obstante, la entrega de tan importante reconocimiento a figuras de las más altas esferas del Partido Fascista, especialmente aquellas que se habían desempeñado en cargos cardinales en el fortalecimiento de las relaciones con América, advertían los fuertes vínculos que se desarrollaron entre ambos países durante la década de 1930, y en particular, en los últimos años ${ }^{61}$.

Asimismo, la designación de Ferrara, la cual se dio por su cercanía y pertenencia a la comunidad italiana en Cuba, además de los vínculos que había cultivado con altos mandos del gobierno y la economía de Italia -la muestra de eso fue su rol en los actos oficiales de recibimiento del barco Italia y el aviador Pinedo-, se convirtieron en un potencial ante la necesidad de Cuba para adecuar el intercambio comercial con aquellos países europeos que estaban por entrar, o habían entrado, en guerra. El inicio de la gira del "Enviado Especial" por Italia y España era la muestra que, en ambos casos, dichos países, cultural y

${ }^{59}$ Boletín Oficial de la Secretaría de Estado. La Habana, año XXXVII, enero-marzo, 1940, p. 32.

${ }^{60}$ Boletín Oficial de la Secretaría de Estado. La Habana, año XXXVII, abril-septiembre, 1940, p. 3.

${ }^{61}$ Los políticos condecorados fueron, en los diferentes rangos, lo siguientes: Con el rango de "Gran Cruz" a Galeazo Ciano (ministro de Relaciones Exteriores de Italia). Con el rango de "Gran Cruz de Segundo Grado": Felice Guarnieri, (ministro de Cambios y Divisas extranjeras de Italia), Guiseppe Bastianini, (subsecretario de Relaciones Exteriores de Italia), Amadeo Gianini (director general de Relaciones Comerciales de Italia); "Gran Oficial": ministro Andrea Geisser Celesia Di Vegliasco (jefe de la Oficina de Ceremonial de Italia), ministro Felipo Amfuso (jefe del despacho de S.E del ministro de Relaciones Exteriores de Italia), ministro Nob. Renato Prunas (director general de Relaciones Transoceánicas), Givanni Persico (ministro de Italia en Cuba); en el rango de "Comendador": Dr. Angiolo Cassinis (vicedirector general de Relaciones Comerciales de Italia), Umberto Natali (cónsul general, jefe de la secretaría particular de S.E del ministro de Relaciones Exteriores de Italia), Marcello del Drago del Principi D’Antuni (primer secretario de legación de la Oficina del Ceremonial de Italia), Giorgio Benzoni Dei Marchesi Di Balsamo (cónsul de primera clase, jefe de la Oficina de la Dirección General de Relaciones Comerciales de Italia); con el rango de "Oficial": Guiseppe Vitaliano Dei Baroni Confalonieri (jefe de la Oficina de la 4ta. Dirección General de Relaciones Transoceánicas de Italia), Duque Paolo Gallier De la Tour (primer secretario de legación en la Oficina del Ceremonial de Italia), Sr. Marqués Blasco Lanza D’Ajeta Dei Principi di Trabia (cónsul del despacho de S.E el ministro de Relaciones Exteriores de Italia), Pier Pasqualle Spinelli (ex primer secretario de la Legación de Italia en Cuba); y con el rango de "Caballero": Barón Carlo de Ferraris Salzano (cónsul del despacho de S.E el ministro de Relaciones Exteriores de Italia), Dr. Federico Sensi (vicecónsul de la Oficina del Ceremonial de Italia). Boletín Oficial de la Secretaría de Estado. La Habana, año XXXVII, enero-marzo, 1940, pp. 32-34. 
económicamente, eran importantes para la economía y la política de Cuba. De igual forma, la entrada de Italia en la guerra y la posterior aplicación de las medidas que Cuba tendría que aplicar a partir del "estado de neutralidad", impedirían cualquier tipo de intercambio comercial, lo que afectaría ostensiblemente las expectativas que Cuba había depositado a partir de la firma del tratado comercial.

Por último, los acuerdos firmados por los representantes de las naciones americanas en la II Reunión de Consultas entre Cancilleres Americanos celebrada en La Habana en $1940^{62}$ acerca de la necesidad de frenar la participación del cuerpo diplomático o consular en actividades políticas en los territorios americanos, fue el primer paso dado por Cuba que marcó un freno a la diplomacia italiana y los métodos que había implementado a la hora de hacer política en América. Además de repeler cualquier actividad dirigida, ayudada o instigada por gobiernos exteriores que pusieran en peligro la tradición democrática de la región, el gobierno de Cuba y las demás delegaciones que allí asistieron manifestaron su disposición a extirpar las doctrinas que ponían en riesgo la neutralidad regional, lo que develó la incompatibilidad de los objetivos de la política exterior italiana para con los países latinoamericanos desde el ascenso del fascismo, en especial, para con Cuba. Italia y Alemania se habían convertido, para 1940, en naciones que esgrimían doctrinas políticas contrarias a la posición que progresivamente fueron asumiendo los gobiernos y las sociedades latinoamericanas una vez que comenzó la guerra. En la mayoría de los casos, dichos países eran vistos como los responsables de la situación bélica mundial que se vivía ${ }^{63}$.

En la medida en que la guerra se fue extendiendo al resto de los países europeos, Cuba fue ampliado la lista de naciones ocupadas ante las cuales se declaraba "neutral"64, mientras que al interior del país el Ejecutivo, en estrecha consonancia con lo que acontecía en Estados Unidos, fue alejándose cada vez más de los países del Eje y tomó medidas que debilitaron las relaciones diplomáticas con Italia ${ }^{65}$. Así, cuando el lunes 8 de diciembre de 1941 Estados Unidos declaró la guerra a Japón, ya Cuba había dado avances de la posición que tomaría frente al ataque japonés en el Pacífico, ya que el propio presidente de Cuba había solicitado

62 Se celebró en La Habana del 21 al 30 de julio de 1940.

${ }^{63}$ Desde 1939 se habían dado distintos reportes de manifestaciones, tanto políticas como sociales, del malestar que había creado las acciones castrenses de Alemania y más tarde Italia, en junio de 1940. Diario de La Marina, La Habana, 11 de junio, 1940, p. 11; Diario de La Marina, La Habana, 11 de junio, 1940, p. 12.

${ }^{64}$ Diario de La Marina, La Habana, 12 de mayo, 1940, p. 1.

65 Una de las medidas aplicadas por Cuba que tensó las relaciones entre Cuba e Italia antes que ambos países rompieran relaciones fue la incautación de navíos de países beligerantes en aguas cubanas. El 27 de junio de 1940 y amparándose en una la Ley de Espionaje de 1917, el presidente norteamericano autorizó la apropiación de buques extranjeros que se encontraban en aguas jurisdiccionales de este país en el caso de que estos fueran necesarios para la protección de los intereses nacionales o la seguridad de los propios buques. Siguiendo instrucciones, y en la medida de que se fue polarizando más la situación con Italia, Cuba, respecto al barco de bandera italiana Recca, el cual había llegado a puerto cubano en calidad de refugiado en el mes de junio de 1941 procedente de Génova y Cádiz, aplicó la misma medida en marzo de 1941 mediante el decreto 2438 por el que se resolvía la incautación del buque. El mismo pasaría a formar parte de la Marina de Guerra y se le cambió el nombre por el de Libertad. Diario de La Marina, La Habana, 28 de junio, 1940, p. 10; Boletín Oficial de la Secretaría de Estado. La Habana, año XXXVIII, julio-agosto-septiembre, 1941, p. 36. 
al Congreso, unas horas antes, la aprobación de la Ley de Emergencia Nacional y la aplicación de la Ley de Defensa de la Democracia "(...) para contribuir con nuestro esfuerzo, dentro de la cooperación establecida entre las naciones democráticas del mundo, para vencer las ambiciones sin límites del más peligroso cesarismo (...)"66.

Así, el 9 de diciembre de 1941, seguido de una solemne alocución al pueblo de Cuba por parte del presidente Batista, el gobierno de Cuba declaró la guerra a Japón mediante resolución conjunta votada por el Congreso ${ }^{67}$, y dos días más tarde hizo lo mismo con el Reich alemán y el Reino de Italia ${ }^{68}$, dando por terminados años de cordial relación entre Cuba e Italia, además de que firmó una serie de decretos que estuvieron, la mayoría, orientados a reglamentar la situación comercial, política y social respecto a dichos países ${ }^{69}$. Precisamente, algunos de estos decretos estuvieron dirigidos a la regulación del comportamiento y el futuro de los ciudadanos italianos -junto con los alemanes y japoneses- que se encontraban residiendo en el país. En guerra contra los países del Eje, Cuba se sumaría a conjunto de países de la región que, además de declarar la guerra y romper relaciones con Japón, Italia y Alemania, tomaron medidas drásticas contra los nacionales de esos países en nombre de la seguridad.

\section{Consideraciones finales}

Como se ha esbozado, la política exterior de la Italia fascista para con el continente latinoamericano, en particular para con Cuba, fue un elemento indispensable para la modelación de los posicionamientos políticos, sociales y culturales del país respecto a Italia y, por consiguiente, para con el fascismo. A diferencia de lo plantea la historiografía clásica que ha abordado las relaciones

66 Diario de La Marina, La Habana, 7 de diciembre, 1941, p. 1.

67 Boletín Oficial de la Secretaría de Estado. La Habana, año XXXVIII, octubre-noviembre-diciembre, 1941 , p. 114.

68 Boletín Oficial de la Secretaría de Estado. La Habana, año XXXVIII, octubre-noviembre-diciembre, 1941, p. 114. Este mismo día Estados Unidos declaró la guerra a Italia y Alemania. Diario de La Marina, La Habana, 12 de diciembre, 1941, p. 1.

69 Los decretos más importantes fueron: decreto 3448: mediante el cual se le atribuía carácter de extranjeros enemigos a todos a los ciudadanos o súbditos de una nación enemiga, $u$ aliada del enemigo que se encuentren en territorio de la República. Se fijaba como norma básica la intervención de la propiedad enemiga a los nacionales de países enemigos, así como los aliados de los enemigos, que eran: Alemania, incluyendo los territorios anexados de Austria y Eslovaquia, Japón, incluyendo Karafute, Koea, Kwantung, Formosa y demás islas bajo el mandato japonés, e Italia y sus posesiones del norte de África. Y en carácter de aliados de los países enemigos estaban: Hungría, Rumanía y Bulgaria, Finlandia y Thailand (Siam). Boletín Oficial de la Secretaría de Estado. La Habana, año XXXVIII, octubre-noviembre-diciembre, 1941, p. 189; decreto 3341: mediante el cual se prohibía a los nacionales de países enemigos y/o aliados de los enemigos residir en el litoral de los puertos o lugares de la costa cercanos a los puertos. Se daban 10 días a partir de la publicación del decreto para que todos los nacionales de países enemigos y/o aliados de los enemigos comparecieran en una estación de policía cuya demarcación se encontraba su domicilio, y tenían que informar y justificar cualquier cambio futuro en el domicilio. De no cumplir con lo estipulado en el decreto en no menos de 10 días, serían apresados. Boletín Oficial de la Secretaría de Estado. La Habana, año XXXVIII, octubre-noviembre-diciembre, 1941, pp. 221-222; decreto 3382: por el mismo se creaba el cargo de "Interventor de la Propiedad Enemiga", dándosele determinadas facultades en la fiscalización de las relaciones comerciales de los extranjeros enemigos. Boletín Oficial de la Secretaría de Estado. La Habana, año XXXVIII, octubre-noviembre-diciembre, 1941, pp. 230-231. 
exteriores de Cuba durante el período, se puede comprobar, primero, que la agenda exterior de Cuba no se concentró, exclusivamente, en el desenvolvimiento de vínculos económicos y políticos con Estados Unidos pues, si bien los mismos parecieron simbióticos, el Ejecutivo cubano concertó relaciones con países políticamente fuertes durante los años 1930, como sucedió con la Italia mussoliniana.

Y es que la proximidad que se estableció entre La Habana y Roma, desde 1922 hasta casi el estallido de la Segunda Guerra Mundial, estuvo en correspondencia con el interés manifiesto del país europeo para con la isla. A pesar de que la zona caribeña era considerada como un área de ascendencia económica y política de Estados Unidos, lo cierto es que el Partido Nacional Fascista (PNF) delineó una estrategia de acercamiento para Cuba apoyándose en las relaciones diplomáticas. Mediante los respectivos embajadores italianos llegados al país, se implementó un plan que, en contubernio con la exigua pero influyente comunidad italiana asentada en la isla, parte de la alta burguesía nacional admiradora de Mussolini y el fasci habanero, buscó la exaltación de la latinidad como lazo cultural. Además de presentar ante los ojos de la sociedad cubana los logros del país europeo, se promocionó el fascismo como corriente ideológica, reforzándose la labor proselitista y de búsqueda de respaldo, sobre todo, en 1935 durante la invasión y posterior colonización de Abisinia (actual Etiopía).

Puntualmente, durante dicho período se aprecia un notable acercamiento entre el cuerpo diplomático italiano y la comunidad de emigrados. Con la clara intención de robustecer la propaganda a favor del gobierno de Italia y el fascismo, las principales instituciones perteneciente a la comunidad italiana en La Habana, como la Casa de Italia, la Sociedad Italiana de Asistencia y el Institutito "Vittorio Emmanuele", implementaron un programa de actividades en el que se conjugó el ocio, la exaltación de la cultura, la promoción del asistencialismo, y también la política. Desde esos espacios se alabaron los logros que en materia económica, política y cultural había logrado el país europeo desde el ascenso del fascismo, presentándolo como un modelo a seguir.

Así, para Cuba, el proceso de acercamiento que el gobierno de Italia había iniciado para con sus coterráneos se materializó, con más fuerza, durante el conflicto en África, y se concentró en el incremento de actividades planificadas desde y por la embajada. En sentido general, tales reuniones mostraron un aparente matiz cultural y asociativo pero, en efecto, revistieron una fuerte impronta política-militante al ser los miembros y la directiva del fasci que sesionaba en La Habana, las instituciones culturales y el cuerpo diplomático -fieles emisarios todos del fascismo en el exterior-, sus principales hacedores.

\section{Fuentes}

Franklin D. Roosevelt Presidential Library \& Museum. Diplomatic Correspondence, 1935-1941, Estados Unidos. 


\section{Fuentes Hemerográficas}

Carteles, La Habana, 14 de septiembre,1924.

Carteles, La Habana, 3 de abril,1927.

El Orden. Diario de la Mañana, Santa Fé, Argentina, 8 de marzo, 1928.

El Orden. Diario de la Mañana, Santa Fé, Argentina, 9 de marzo, 1928.

Revista Bohemia, La Habana, 18 de marzo, 1928.

Diario de La Marina, La Habana, 5 de septiembre, 1924.

Diario de La Marina, La Habana, 19 de agosto, 1937.

Diario de La Marina, La Habana, 19 de agosto, 1937.

Diario de La Marina, La Habana, 19 de agosto, 1937.

Diario de La Marina, La Habana, 9 de marzo, 1938.

Diario de La Marina, La Habana, 9 de marzo, 1938.

Diario de La Marina, La Habana, 12 de marzo, 1939.

Diario de La Marina, La Habana, 21 de marzo, 1939.

Diario de La Marina, La Habana, 22 de marzo, 1939.

Diario de La Marina, La Habana, 22 de marzo, 1939.

Diario de La Marina, La Habana, 21 de marzo, 1939.

Diario de La Marina, La Habana, 13 de septiembre,1939.

Diario de La Marina, La Habana, 12 de mayo,1940.

Diario de La Marina, La Habana, 11 de junio,1940.

Diario de La Marina, La Habana, 20 de junio,1940.

Diario de La Marina, La Habana, 28 de junio,1940.

Diario de La Marina, La Habana, 12 de diciembre,1941.

Diario de La Marina, La Habana, 7 de diciembre,1941.

\section{Publicaciones oficiales}

Boletín Oficial de la Secretaría de Estado. La Habana, año XXXIII, octubre, 1935.

Boletín Oficial de la Secretaría de Estado. La Habana, año XXXIII (abril, mayo, junio), 1936.

Boletín Oficial de la Secretaría de Estado. La Habana, año XXXIV (enero, febrero, marzo), 1937.

Boletín Oficial de la Secretaría de Estado. La Habana, año XXXIV, agosto,1937.

Boletín Oficial de la Secretaría de Estado. La Habana, año XXXIV, septiembre,1937. Boletín Oficial de la Secretaría de Estado. La Habana, año XXXIV, diciembre,1937.

Boletín Oficial de la Secretaría de Estado. La Habana, año XXXV, enero,1938.

Boletín Oficial de la Secretaría de Estado. La Habana, año XXXV, junio,1938.

Boletín Oficial de la Secretaría de Estado. La Habana, año XXXV, agosto,1938.

Boletín Oficial de la Secretaría de Estado. La Habana, año XXXVI, julio-agostoseptiembre, 1939.

Boletín Oficial de la Secretaría de Estado. La Habana, Año XXXVI, julio-agostoseptiembre, 1939.

Boletín Oficial de la Secretaría de Estado. La Habana, año XXXVI, octubre,1939.

Boletín Oficial de la Secretaría de Estado. La Habana, año XXXVI, abril-mayojunio, 1939.

Boletín Oficial de la Secretaría de Estado. La Habana, año XXXVII, abrilseptiembre,1940. 
Boletín Oficial de la Secretaría de Estado. La Habana, año XXXVII, octubrediciembre, 1940.

Boletín Oficial de la Secretaría de Estado. La Habana, año XXXVII, eneromarzo, 1940.

Boletín Oficial de la Secretaría de Estado. La Habana, año XXXVII, abrilseptiembre,1940.

Boletín Oficial de la Secretaría de Estado. La Habana, año XXXVII, eneromarzo,1940.

Boletín Oficial de la Secretaría de Estado. La Habana, año XXXVIII, julio-agostoseptiembre,1941.

Boletín Oficial de la Secretaría de Estado. La Habana, año XXXVIII, octubrenoviembre-diciembre,1941.

Boletín Oficial de la Secretaría de Estado. La Habana, año XXXVIII, octubrenoviembre-diciembre, 1941.

Boletín Oficial de la Secretaría de Estado. La Habana, año XXXVIII, octubrenoviembre-diciembre,1941.

\section{Bibliografía}

APELLIUS, Mario. La Isla del rayo verde: Cuba- Jamaica- Puerto Rico-HaitíPequeñas Antillas. Barcelona: Editorial Maucci, 1929.

BATTEMBERG, Domingo. Cuba en 1928: reminiscencias, documentos, informaciones, gráficos, artículos y opiniones del VIl Congreso de la Prensa Latina. París: Universite Paris 3, 1928.

CONSUEGRA SANFIEL, Alberto. Inglaterra, Francia y la Sociedad de Naciones: intereses y actitudes frente al segundo conflicto ítalo-etíope (1935-1936). Contra Relatos desde el Sur. Dic. 2015, año XI, n. 12, pp. 79-95.

DÍAZ MARTíN, Roberto. Etapas en Cuba de cruceros históricos italianos en los años 20 del siglo XX. El Barco "Italia" y el vuelo de Francesco Pinedo. En: CAMPOLONGO, D. Emigrazione y presenza italiana in Cuba. Vol. VII. Circolo culturale B.G. Duns Scoto, 2005.

Ecured. Alba de Céspedes [en línea]. [Consulta: 30-04-2018] Disponible en $<$ https://www.ecured.cu/Alba de C\%C3\%A9spedes $>$.

FABIANO, D. I fasci italiani all'estero. En: BEZZA, B. (ed.). Gli italiani fuori d'Italia. Gli emigrati italiani nei movimenti operai dei paesi d'adozione. Milan: Angeli, 1983.

FOX, J.C. Film propaganda in Britain and Nazi Germany: World War II cinema. Oxford: Berg, 2007.

GONZÁLEZ, Froilán y CUPULL, Adys. Julio Antonio Mella y Tina Modotti contra el Fascismo. Ciudad de La Habana: Casa Editora Abril, 2005.

IBARRA, Jorge. Historiografía y Revolución. Temas. Ene./Mar. 1995, n. 1, pp. 4-14. 
LARA, Martín. Historiografía cubana. Entrevista a Óscar Zanetti Lecuona. RIRA. Oct. 2016, vol. 1, n. 2, 2016, pp. 201-213.

LEPKOWSKI, Tadeusz. Problemas controvertibles de una síntesis de la historia de Cuba. Estudios Latinoamericanos. 1972, n.1, pp. 101-154.

MELLA, Julio Antonio. Documentos y artículos. La Habana: Editorial Ciencias Sociales, 1975.

MONTES PÉREZ, Carlos. Cuerpos representados, cuerpos dominados. Poder y representación en los carteles de propaganda nazi Thémata. Revista de Filosofía. 2012, n. 46, pp. 707-716.

NAVARRETE, Williams. El enigma de una ítalo-cubana en París. El Nuevo Herald [en línea]. 2016. [Consulta: 30-04-2018]. Disponible en <http://www.elnuevoherald.com/vivir-mejor/artes-letras/article91362537.html>.

NYE, Joseph S. The Changing Nature of World Power. Political Science Quarterly. 1990, vol. 105, n. 2, pp. 177-192.

NYE, Joseph S. Soft power. The means to success in World Politics. Nueva York: PublicAffairs, 2004.

ROJAS, Rafael. Caminos de la historia crítica. Cuban Studies. 2015, n. 43, pp. 135140.

ROJAS, Rafael. El nuevo texto de la Revolución. En: LLANO PULIDO, G.; AYALA, M. y CONSUEGRA SANFIEL, A. Mirando a Cuba. Reformas y configuraciones en una nueva etapa. Buenos Aires: Imago Mundi, 2016.

SAVARINO, Franco. Apuntes sobre el fascismo italiano en América Latina (19221940). Reflejos, Revista de la Universidad de Jerusalén. 2000-2001, n. 9, pp. 100-110.

SEARA VÁZQUEZ, Modesto. La paz precaria. De Versalles a Danzig (II). México: Facultad de Ciencias Políticas y Sociales, 1970. 